\title{
ANNUAL TECHNICAL PROGRESS REPORT OF RADIOISOTOPE POWER SYSTEM MATERIALS PRODUCTION AND TECHNOLOGY PROGRAM TASKS FOR OCTOBER 1, 2002 THROUGH SEPTEMBER 30, 2003
}

\author{
Prepared for Department of Energy \\ Office of Space and Defense Power Systems \\ under Budget and Reporting Classification \\ AF 701020 0, AF 706000 0, AF 703000 0, \\ AF 011010 0, AF 011040 0, 40041600 0, \\ 400409600,400413000 , and 040414000
}

by

Radioisotope Power System Program

Metals and Ceramics Division

Oak Ridge National Laboratory

Oak Ridge National Laboratory

Oak Ridge, Tennessee 37831-6080

operated by UT-Battelle, LLC

for the

U.S. Department of Energy

Contract DE-AC05-00OR22725 
This page intentionally blank 


\section{CONTENTS}

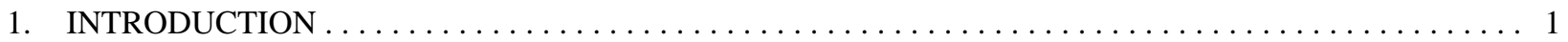

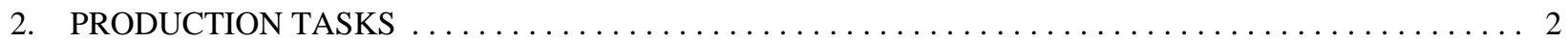

2.1 CARBON-BONDED CARBON FIBER INSULATOR SETS $\ldots \ldots \ldots \ldots \ldots \ldots \ldots \ldots \ldots \ldots \ldots 2$

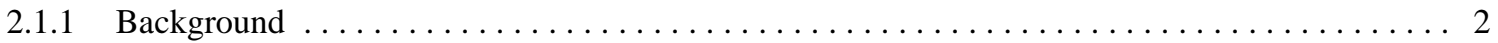

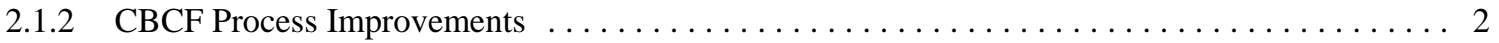

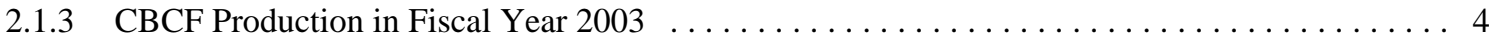

2.2 IRIDIUM-ALLOY BLANK AND FOIL PRODUCTION $\ldots \ldots \ldots \ldots \ldots \ldots \ldots \ldots \ldots \ldots \ldots$

2.2.1 Preparation of DOP-26 Iridium Alloy Blanks $\ldots \ldots \ldots \ldots \ldots \ldots \ldots \ldots \ldots \ldots \ldots \ldots \ldots$

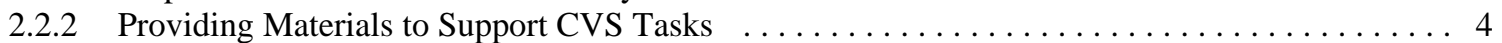

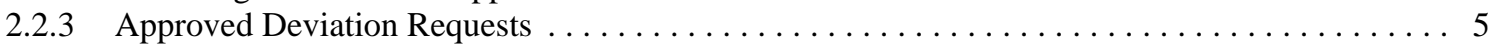

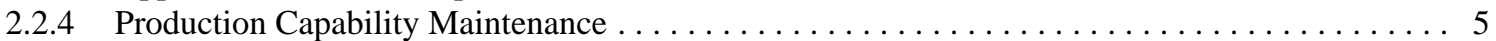

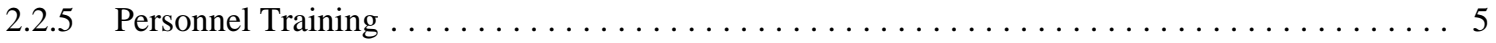

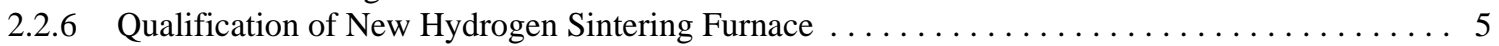

2.2.7 Preparation of Master Alloys . . . . . . . . . . . . . . . . . . . . . . . . . . . . . . 5

2.2.8 Removal of Thorium From Iridium Alloy Scrap $\ldots \ldots \ldots \ldots \ldots \ldots \ldots \ldots \ldots \ldots \ldots \ldots \ldots$

2.3 IRIDIUM ALLOY BLANK PRODUCTION FOR NASA $\ldots \ldots \ldots \ldots \ldots \ldots \ldots \ldots \ldots \ldots \ldots$

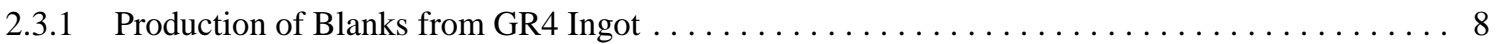

2.3.2 Processing of G5 Ingot for the Production of Blanks $\ldots \ldots \ldots \ldots \ldots \ldots \ldots \ldots \ldots \ldots \ldots$

2.3.3 Processing of G6 Ingot for the Production of Blanks $\ldots \ldots \ldots \ldots \ldots \ldots \ldots \ldots \ldots \ldots$

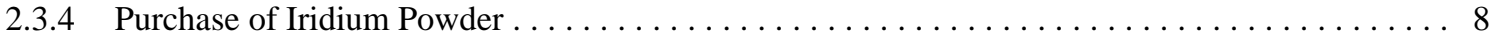

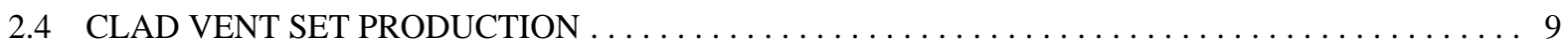

2.4.1 Clad Vent Sets for DOE Maintenance Production $\ldots \ldots \ldots \ldots \ldots \ldots \ldots \ldots \ldots \ldots \ldots \ldots$

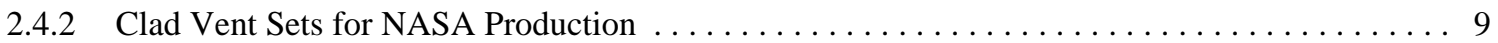

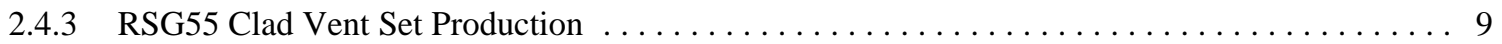

2.4.3.1 Single-Draw Forming Process Evaluation and Development $\ldots \ldots \ldots \ldots \ldots \ldots .10$

2.5 IRIDIUM POWDER INVENTORY MANAGEMENT $\ldots \ldots \ldots \ldots \ldots \ldots \ldots \ldots \ldots \ldots \ldots \ldots \ldots$

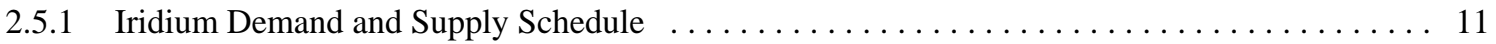

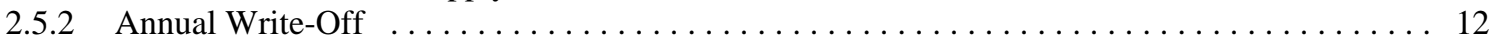

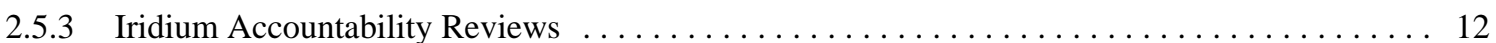

2.5.4 Report of Method for Removal of Thorium from Iridium Scrap $\ldots \ldots \ldots \ldots \ldots \ldots \ldots \ldots$

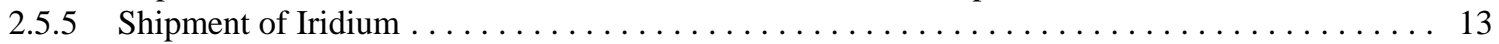

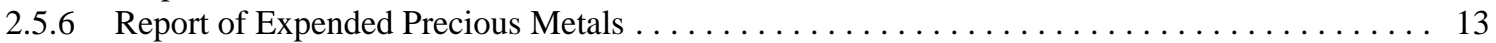

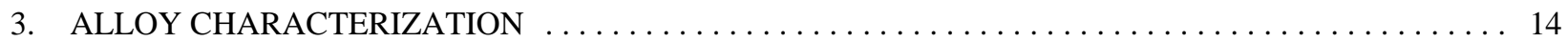

3.1 EFFECTS OF AGING FOR UP TO FOUR MONTHS AT $500-700^{\circ} \mathrm{C}$ ON THE TENSILE

PROPERTIES OF MO-41\%RE . . . . . . . . . . . . . . . . . . . . . . . . . . 14

3.2 COMPATIBILITY OF HAYNES ALLOY 25 WITH GRAPHITE $\ldots \ldots \ldots \ldots \ldots \ldots \ldots \ldots \ldots$

3.3 TECHNICAL SUPPORT FOR THE IHS70 PROGRAM $\ldots \ldots \ldots \ldots \ldots \ldots \ldots \ldots \ldots \ldots \ldots \ldots$

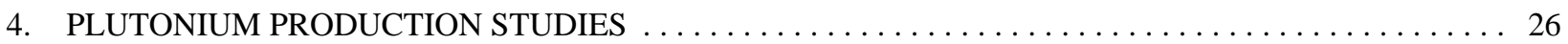

4.1 EVALUATION OF THE RADIOLYTIC DECOMPOSITION OF MOISTURE SORBED ON $\mathrm{NPO}_{2}$. 26

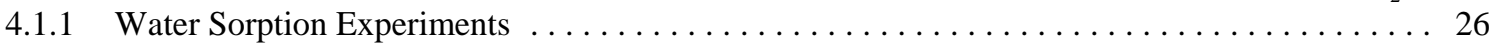

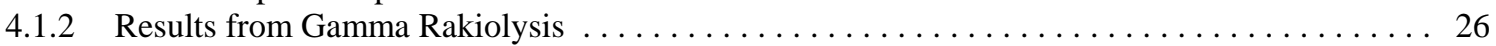

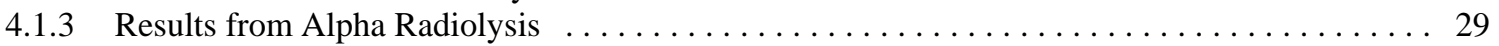

4.2 ARRAY TARGET POST-IRRADIATION EXAMINATION $\ldots \ldots \ldots \ldots \ldots \ldots \ldots \ldots \ldots \ldots \ldots$

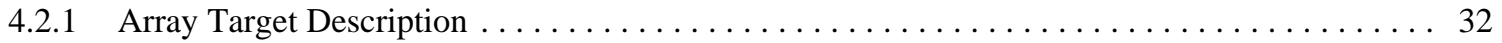

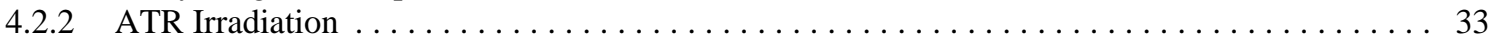

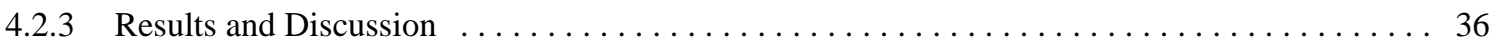


This page intentionally left blank 


\section{INTRODUCTION}

The Office of Space and Defense Power Systems of the Department of Energy (DOE) provides Radioisotope Power Systems (RPS) for applications where conventional power systems are not feasible. For example, radioisotope thermoelectric generators were supplied by the DOE to the National Aeronautics and Space Administration for deep space missions including the Cassini Mission launched in October of 1997 to study the planet Saturn. The Oak Ridge National Laboratory (ORNL) has been involved in developing materials and technology and producing components for the DOE for more than three decades. For the Cassini Mission, for example, ORNL was involved in the production of carbon-bonded carbon fiber (CBCF) insulator sets, iridium alloy blanks and foil, and clad vent sets (CVS).

This report has been divided into three sections to reflect program guidance from the Office of Space and Defense Power Systems for fiscal year (FY) 2003. The first section deals primarily with maintenance of the capability to produce flight quality (FQ) CBCF insulator sets, iridium alloy blanks and foil, and CVS. In all three cases, production maintenance is assured by the manufacture of limited quantities of FQ components. The second section deals with several technology activities to improve the manufacturing processes, characterize materials, or to develop technologies for new radioisotope power systems. The last section is dedicated to studies related to the production of ${ }^{238} \mathrm{Pu}$. 


\section{PRODUCTION TASKS}

\subsection{CARBON-BONDED CARBON FIBER INSULATOR SETS}

\subsubsection{Background}

The CBCF production facilities have been operated in a production maintenance mode since the Cassini campaign to produce Flight Quality parts of insulation material. Dedicated facilities for CBCF production remain in the Carbon Materials Technology Laboratory of ORNL. Qualification of fifteen CBCF sleeves produced in FY 2000 were the first to be fully characterized as Flight Quality in nearly a decade. During much of the 1990's CBCF production was directed at making experimental variations of CBCF that explored the potential for improved insulating attributes at very high temperatures. The effect of brief excursions to reentry temperatures was also explored.

The impurity content of CBCF insulators produced in FY 2001 and FY 2002 had become an issue with respect to qualifying Flight Quality insulators. Ca concentrations as high as $2500 \mu \mathrm{g} / \mathrm{g}$ and Si concentrations as high as 510 $\mu \mathrm{g} / \mathrm{g}$ were found in some samples. The specification allowable is $200 \mu \mathrm{g} / \mathrm{g}$ and $300: \mathrm{g} / \mathrm{g}$, respectively. An extensive assessment of CBCF raw materials, procedures, processes and equipment yielded numerous opportunities for making CBCF having lower impurity content. All opportunities were implemented in FY 2003 resulting in a significant reduction in impurities and the successful production of Flight Quality CBCF insulators. Alternate approaches, including Glow Discharge Mass Spectroscopy (GDMS) and Inductively Coupled Plasma - Atomic Emission Spectroscopy (ICP-AES) were employed to assess the impurities in CBCF and raw materials.

\subsubsection{CBCF Process Improvements}

\section{$\underline{\text { Raw Materials }}$}

Initially, the process water supply in the CBCF laboratory was suspected to be the source of excessively high levels of $\mathrm{Ca}$ and $\mathrm{Si}$ in CBCF insulators. Although replaceable water filters were employed to screen the water used for slurry preparation, a significant length of conduit down stream from the filters maintains residual water after use. The net result is that calcium and other deposits have formed over the years. The water filtration system was replaced with pharmaceutical grade filters and conduit. Additional precautions were taken to assure the quality of the process water. The process water typically carries 50: g/g of dissolved calcium. Since the as-molded insulators contain about $50 \%$ by weight water, the maximum calcium level that could be attributed to the water is about 50: $\mathrm{g} / \mathrm{g}$. This is well within the specification allowable.

A sample of carbonized rayon fiber used for CBCF production was routinely analyzed by spark source mass spectroscopy (SSMS) for impurities. The contribution to total impurities attributable to the carbon fiber was typically less than one third of the total measured. Occasionally an anomalously high sodium concentration is measured in one of three outgassed samples. The sodium can be attributed to the processing of the rayon tow. We have a reserve of approximately one ton of aerospace grade rayon tow in storage for CBCF production. An additional quantity of rayon will be chopped in early FY 2004.

An additional 200 lbs of Durez 22352 resin was purchased to the program specification MET-CER-MS-14, Rev. No. 6. Although this material is out of commercial production, Durez Corporation was able to produce a small quantity with the same raw materials using their pilot production facility. This new lot resin was found to be dramatically lower in impurities when compared to the previous lot in use since 1990. Ca was several times lower and Si was two orders of magnitude lower. Acceptance of the resin according to the purchase specification requires the fabrication of a set of CBCF sleeves. Characterization of samples from those sleeves must be within the CBCF specification. Samples from E15 sleeves met all specifications including the requirement on impurities.

\section{Carbonization of Rayon and Fiber Wetting}

In the course of producing CBCF insulators in FY 2003 an important discovery was made that relates to fiber wetting in slurry preparation. A carbon fiber/water slurry was being prepared for a molding run of nine sleeves using lot \#56 of carbonized rayon fibers. This lot of fibers was carbonized a week prior to the start of slurry preparation and maintained under a nitrogen blanket in the carbonization furnace until use. The rayon fiber was carbonized at $1400^{\circ} \mathrm{C}$ under a nitrogen cover gas. The fiber was taken directly from the carbonization furnace to slurry preparation. The ease 
of fiber wetting in the initial stage of slurry preparation was dramatically improved compared to that usually experienced when the carbonized fiber is shelved for some time prior to use. This practice will be made part of our standard procedure. Insulators made using this improved slurry preparation approach were closer to the mean specification on density and were free of surface defects that had been recently problematic for the production of CBCF disks.

\section{Carbon Fiber Slurry Preparation}

Ultrasonic Horn: A titanium ultrasonic horn is used to aid mixing in the "Slurry Preparation Stage". Some CBCF samples from FY 2001 and FY 2002 production exhibited Ti, Al and V levels exceeding 50: g/g, the specification limit on these impurities. The likely source of these elements is metal particles generated by microcavitation at the tip of the ultrasonic horn. Significant sample-to-sample variation in impurity levels suggests that these impurities entered the process in a particulate form. Erosion of the tips appeared to have accelerated with continued use. New horn tips were purchased and will be carefully monitored and replaced frequently to avoid excessive cavitation.

Milling Jar: The procedure for slurry preparation requires the use of a polyethylene lined milling jar. It was discovered that the milling jars historically used for CBCF production had a polyurethane liner. Although this material was selected for abrasion resistance, it had begun to break down with use and was identified as a potential source of contamination. Milling jars were replaced with jars fabricated from ultrahigh molecular weight polyethylene to be consistent with procedural requirements.

Zirconia Media: Zirconia milling media approximately 3/8 in. diameter x 3/8 in. high are used to refine the carbon fiber/water slurry by tumbling for about 4 minutes in the polyethylene milling jar. In the course of assessing all potential sources of impurities, it was noted that the zirconia milling media that had been historically used for CBCF production was calcia stabilized zirconia. This material is rather soft and generates measurable quantities of abrasion product even after 4 minutes of milling. The calcia-stabilized zirconia milling media was replaced with yttria-stabilized zirconia media. The new milling media is extremely resistant to abrasion and showed no signs of contributing to elevated impurity levels in CBCF.

Drying, Curing and Carbonization of CBCF Insulators

No potential sources of contamination were identified for these stages of the process.

Machining and Inspection

Cleanliness of tooling and handling was emphasized.

Vacuum Outgassing

Samples are outgassed in a high temperature vacuum furnace at $1500^{\circ} \mathrm{C}$ and $<5 \times 10^{-5}$ torr prior to characterization including impurity determination. During outgassing samples are at risk of contamination if a previous heat treatment left behind a mobile contaminant. It is also critical to have the vacuum system operating properly since the diffusion pump operates with silicone oil. The addition of impurities during outgassing of samples has not been problematic for recent production.

\section{Packaging}

Metallic sample boxes (ointment cans as defined in procedure No. MET-CER-SOP-37, Rev. 4) are used to contain CBCF samples after machining and outgassing to protect them from being crushed. Polyethylene foam cut to fit and further protect the samples is also included in the sample cans. It was noted that an almost perceptible film coated the inside of the ointment cans. The total quantity was determined to be about one mg per can. A concentrated sample of this residual film was analyzed by ICP AES and shown to be high in Ca and Si. Further evaluation of the polyethylene foam showed it to be high in Ca and Si. Results from ICP-AES and XRD confirmed the foam to contain talc. Discussion with the vendor indicated that this foam is produced with a talc foaming agent that is added at $1 \mathrm{wt}$. \% to promote the heterogeneous formation of bubbles. To remain consistent with numerous procedures that call for the use of polyethylene foam, polyethylene foam clad on both sides with polyethylene film was procured for future use in packaging.

An Assessment of Using Glow Discharge Mass Spectroscopy for Impurity Analysis of CBCF 
Impurity analysis of CBCF insulation is presently performed by Analytical Chemistry Organization at BWXT-Y12 using Spark Source Mass Spectroscopy (SSMS) in accordance with Procedure AC-MM-4 0203, Rev. A. Recent concerns regarding impurity levels in CBCF prompted an assessment of Glow Discharge Mass Spectroscopy (GDMS) for making these impurity measurements. Parallel analysis of carbon standards and CBCF samples by GDMS and SSMS supports a conclusion that GDMS is a valid method for the determination of impurities in CBCF. GDMS analysis is about a factor of four less expensive than SSMS because the data reduction is fully automated. The accuracy of the method does not appear to be any better that SSMS. The principal advantage of SSMS is in the greater mass of the sample evaluated, several mg compared to several : $\mathrm{g}$ for GDMS. The RPS program will continue to use SSMS for the determination of impurities in CBCF. GDMS may be used occasionally to corroborate results.

\subsubsection{CBCF Production in Fiscal Year 2003}

Resolution of issues related to elevated impurity levels in CBCF allowed for the production of flight quality insulators in FY 2003. Eight Flight Quality CBCF Sleeves and more than forty Flight Quality CBCF disks were produced using the existing reserve of Durez 22352 resin. Five CBCF sleeves were produced for the acceptance of a new lot of Durez 22352 resin. The extensive measures taken to clean up the CBCF production process and the qualification of a lower impurity resin will dramatically improve the prospects of producing Flight Quality CBCF insulators in the future.

\subsection{IRIDIUM ALLOY BLANK AND FOIL PRODUCTION}

The goals for this activity are to maintain production capability, to produce a limited number of flight-quality blanks and foil under full configuration control, and to supply materials needed for clad vent set demonstration and maintenance activities. During FY 2003 a total of 23 blanks were produced from the G3 ingot and transferred to the CVS task. An additional 30 flight-quality blanks from G3 ingot were removed from storage and transferred to the CVS task. Iridium alloy scrap blanks and foil were provided for training and development use and for liners used in heat-treating. Maintenance work was performed on the 1200-ton extrusion press and a scrap iridium-alloy ingot was extruded to maintain capability. A technician was hired and trained on many aspects of the processing. A new hydrogen-atmosphere sintering furnace was installed and qualified for use in sintering iridium alloy compacts. A method was demonstrated for removal of thorium from iridium alloy scrap to make it acceptable to commercial refiners.

\subsubsection{Preparation of DOP-26 Iridium Alloy Blanks}

Visual inspection was completed for 16 blanks from sheets G3-13 through G3-16, which had been processed in FY 2002. Three of these blanks showed visual indications of inclusions. These blanks were reworked by sanding together with 7 other blanks from the G3 ingot also identified to have visual indications of inclusions. All 10 of the reworked blanks passed dye penetrant and visual inspections. A data package was prepared for the 10 reworked blanks and 13 prime blanks. A total of 23 blanks from ingot G3 were transferred to the CVS task on January 27, 2003.

In addition, a total of 30 flight-quality blanks from G3 ingot were removed from storage and transferred to the CVS task on December 4, 2002. The blanks consisted of: 30 prime blanks stored on September 26, 2002.

\subsubsection{Providing Materials to Support CVS Tasks}

A total of 38 blanks produced from iridium alloy scrap material were transferred to the CVS task for use in training.

A total of 12 pieces of iridium alloy scrap was rolled to foil and corrugated. The foil was transferred to the CVS task for use as a support in heat-treating operations.

An additional 5 pieces of iridium alloy scrap foil were transferred to the CVS task for use as a support in heat-treating operations.

\subsubsection{Approved Deviation Requests}


Two deviation requests were approved by the iridium configuration control board and distributed in accordance with the interface working agreement.

DR-Ir-209. The sampling and cleaning procedure for iridium alloy foil (MET-MatP-SOP-88) was revised to delete separate thorium samples, cutting of GDMS sample with a diamond saw rather than shears, and to add more detailed instructions on ultrasonic cleaning of samples. The procedure now follows closely the procedure used for cleaning and sampling of iridium alloy blanks.

DR-Ir-210. The procedure for iridium alloy powder processing (MET-MatP-SOP-72) was revised to use an Inconel alloy boat rather than stainless steel during sintering of iridium compacts. The use of tungsten liner in the boat was also added. These changes minimize the potential for contamination of the compacts and for warping of the boat.

\subsubsection{Production Capability Maintenance}

Repair work on the 1200-Ton extrusion press was completed including the complete disassembly and repair of the main 4-way valve. The press is now operational although periodic operational difficulties arise. Often these are from internal leakage through valves which are difficult to diagnose. In order to demonstrate the continued capability and to maintain skills of personnel, an iridium alloy scrap ingot was extruded to sheet bar. Chemical removal of the molybdenum can material from the extrusion was also completed.

\subsubsection{Personnel Training}

The technician apprentice, who has been trained in iridium alloy processing for the past seven months, has been hired as a regular employee effective January 13, 2003. This technician also has been trained in the preparation of iridium powder master blends (operation 3 of MET-MatP-SOP-72). Training of inspection personnel on upgraded equipment used for ultrasonic inspection of blanks was completed on August 2003.

\subsubsection{Qualification of New Hydrogen Sintering Furnace}

A new furnace was installed for sintering iridium alloy powder compacts in a hydrogen atmosphere. An equipment operating procedure was approved for using this furnace with a hydrogen atmosphere. The furnace is a split tube furnace with an Inconel retort of $125 \mathrm{~mm}$ ID that is dedicated for iridium use only. To qualify the furnace a limited number of iridium powder compacts were heated in the furnace and then processed through vacuum out-gassing and electron-beam melting. Samples from two electron-beam melted buttons were chemically analyzed by glow discharge mass spectrography (GDMS) and were found to be within specification limits with typical low impurity contents. The results of the analysis are shown in Table 1.1.

\subsubsection{Preparation of Master Alloys}

A special instruction deviation request (SIDR-Ir-80) for preparation of iridium master alloy was accepted for use. A draft revision of procedure MET-MatP-SOP-90 was used to prepare about 200 grams each of Ir- $2 \% \mathrm{Al}$ and Ir-2\% Th master alloys. These master alloys will be used to produce a two DOP-26 alloy buttons of about $1 \mathrm{~kg}$ each. The buttons will be analyzed using approved methods for blank material and the results of this analysis will be used to qualify the master alloy for production use. Direct analysis of the master alloys was last performed 10 years ago using equipment that longer exists. Development of new methods for direct analysis of master alloy material is deemed to be neither practical nor economical, due to the infrequency of their use. 
Table 1.1. Chemical Composition of Iridium Powder Compacts Sintered in Thermcraft Tube Furnace and Then Vacuum Out-gassed and Electron-beam Melted

\begin{tabular}{|c|c|c|c|c|c|}
\hline Element & $\begin{array}{l}\text { G19-1thru } 7 \\
\text { Concentration } \\
\text { [ ppm wt ] }\end{array}$ & $\begin{array}{l}\text { G19-29thru } 35 \\
\text { Concentration } \\
\text { [ ppm wt ] }\end{array}$ & Element & $\begin{array}{l}\text { G19-1thru } 7 \\
\text { Concentration } \\
\text { [ ppm wt ] }\end{array}$ & $\begin{array}{l}\text { G19-29thru } 35 \\
\text { Concentration } \\
\text { [ ppm wt ] }\end{array}$ \\
\hline $\mathrm{Li}$ & $<0.01$ & $<0.01$ & $\mathrm{Y}$ & 0.02 & 0.02 \\
\hline $\mathrm{Be}$ & $<0.01$ & $<0.01$ & $\mathrm{Zr}$ & 0.51 & 0.47 \\
\hline B & 0.06 & 0.04 & $\mathrm{Nb}$ & 0.15 & 0.23 \\
\hline C & $<1$ & 1.2 & Mo & 4.8 & 6.5 \\
\hline $\mathrm{N}$ & 1.3 & 2.1 & $\mathrm{Ru}$ & 14 & 14 \\
\hline $\mathrm{O}$ & 4.4 & 7.7 & $\mathrm{Rh}$ & 0.41 & 0.77 \\
\hline $\mathrm{F}$ & $<0.1$ & $<0.1$ & $\mathrm{Pd}$ & $<0.01$ & $<0.01$ \\
\hline $\mathrm{Na}$ & $<0.01$ & $<0.01$ & $\mathrm{Ag}$ & $<0.05$ & $<0.05$ \\
\hline Mg & $<0.01$ & $<0.01$ & $\mathrm{Cd}$ & $<0.05$ & $<0.05$ \\
\hline $\mathrm{Al}$ & $<0.01$ & $<0.01$ & In & $<0.01$ & 0.03 \\
\hline $\mathrm{Si}$ & 2 & 2.2 & Sn & $<0.05$ & $<0.05$ \\
\hline $\mathrm{P}$ & $<0.01$ & $<0.01$ & $\mathrm{Sb}$ & $<0.05$ & $<0.05$ \\
\hline $\mathrm{S}$ & $<0.01$ & $<0.01$ & $\mathrm{Te}$ & $<0.01$ & $<0.01$ \\
\hline $\mathrm{Cl}$ & $<0.05$ & $<0.05$ & I & $<0.01$ & $<0.01$ \\
\hline K & $<0.05$ & $<0.05$ & Cs & $<0.01$ & $<0.01$ \\
\hline $\mathrm{Ca}$ & $<0.05$ & $<0.05$ & $\mathrm{Ba}$ & $<0.01$ & $<0.01$ \\
\hline Sc & $<0.005$ & $<0.005$ & $\mathrm{La}$ & $<0.01$ & $<0.01$ \\
\hline $\mathrm{Ti}$ & 2.1 & 1.9 & $\mathrm{Ce}$ & $<0.01$ & $<0.01$ \\
\hline V & 0.1 & 0.09 & $\mathrm{Hf}$ & 0.52 & 0.67 \\
\hline $\mathrm{Cr}$ & 0.009 & 0.0072 & Тa & 1.5 & 1.7 \\
\hline $\mathrm{Mn}$ & $<0.01$ & $<0.01$ & W & 2800 & 2590 \\
\hline $\mathrm{Fe}$ & 0.046 & 0.026 & $\operatorname{Re}$ & 1.4 & 1.8 \\
\hline Co & $<0.005$ & $<0.005$ & Os & 0.25 & 0.23 \\
\hline $\mathrm{Ni}$ & $<0.01$ & $<0.01$ & $\mathrm{Ir}$ & Matrix & Matrix \\
\hline $\mathrm{Cu}$ & $<0.05$ & $<0.05$ & $\mathrm{Pt}$ & 0.94 & 1.6 \\
\hline Zn & $<0.01$ & $<0.01$ & $\mathrm{Au}$ & $<0.5$ & $<0.5$ \\
\hline $\mathrm{Ga}$ & $<0.05$ & $<0.05$ & $\mathrm{Hg}$ & $<0.1$ & 0.11 \\
\hline $\mathrm{Ge}$ & $<0.1$ & $<0.1$ & $\mathrm{Tl}$ & 0.01 & 0.04 \\
\hline As & $<0.01$ & $<0.01$ & $\mathrm{~Pb}$ & $<0.01$ & $<0.01$ \\
\hline Se & $<0.1$ & $<0.1$ & $\mathrm{Bi}$ & 0.05 & 0.07 \\
\hline $\mathrm{Br}$ & $<0.05$ & $<0.05$ & Th & 0.016 & 0.018 \\
\hline $\mathrm{Rb}$ & $<0.01$ & $<0.01$ & $\mathrm{U}$ & $<0.01$ & $<0.01$ \\
\hline $\mathrm{Sr}$ & $<0.05$ & $<0.05$ & & & \\
\hline
\end{tabular}

\subsubsection{Removal of Thorium from Iridium Alloy Scrap}

A study was performed with the goal of demonstrating treatment of iridium alloy scrap to reduce the thorium content of the material. The level of thorium in most scrap of about 20 to $60 \mathrm{ppm}$ is not acceptable to commercial refineries. The scrap is in a number of forms. The majority of the scrap is in the form of dried grinding sludge. These contain approximately $60 \%$ DOP-26 iridium alloy with the remainder mostly aluminum oxide abrasive particles. The experimental method of thorium removal followed previously described method of melting iridium scrap in molten manganese metal followed by dissolution of the manganese in acid solutions. (B. Heshmatpour and R.L. Heestand, Recovery of Iridium from Scrap Residues, J. of the Less Common Metals 105 (1985) pp. 119-128).

In the initial trial, a total of 1200 grams of the scrap powder was melted with 2800 grams of manganese metal flake. The iridium scrap used in this study was in the form of dried grinding sludge. The nominal iridium content of this material is $60 \%$ with the remainder expected to be mostly alumina grinding media. The materials were induction melted in an 
alumina crucible with an argon cover gas. Due to a heavy oxide on the manganese flake material, electromagnetic coupling was not good and melting did not occur until well above the estimated melting temperature of 1450/ C. This resulted in cracking of the crucible. The solidified metal from this melt was mostly recovered from the space between the alumina crucible and an outer graphite container. The melted material was collected and judged suitable for further use in the experimental process. The material was crushed to a coarse powder and then dissolved in aqueous solutions of $\mathrm{HCl}$ at room temperature. In one test, $100 \mathrm{~g}$ of the powder was dissolved in $200 \mathrm{ml}$ of $20 \%$ (by vol.) concentrated $\mathrm{HCl}$. The solids were removed by filtering and then redissolved a total of ten times to achieve a final weight of $20.7 \mathrm{~g}$ of solids. In a second test, 100 grams of crushed coarse powder was dissolved in $200 \mathrm{ml}$ of $10 \%$ (by vol.) concentrated $\mathrm{HCl}$ and additional acid added to obtain a final solution of $340 \mathrm{ml}$ of $47 \%$ (by vol.) concentrated $\mathrm{HCl}$ added. This was repeated 3 more times with additions of 31 to $41 \%$ (by vol.) concentrated $\mathrm{HCl}$ to achieve a final weight of 22.5 grams.

A magnesia crucible was used for a second trial melt of manganese with the iridium alloy scrap. The crucible cracked during heating as well as during cooling. A zirconia crucible was used for refining of iridium scrap after both alumina and magnesia crucibles were found to be unacceptable. The use of zirconia does have some risk of thorium pickup from impurities in the zirconia. Zirconia does contain thorium as a naturally occurring impurity such that these crucibles require special handling for disposal. The use of the zirconia crucible for direct melting of scrap with manganese flake using a graphite susceptor resulted in unacceptable oxidation of susceptor. Manganese flake was then melted separately using the graphite susceptor without difficulty due to the lower melting temperature of the pure manganese. Direct coupling without a susceptor then remelted the solid manganese. The solid manganese was then again melted with Ir scrap without the use of a susceptor. This was determined to be the best practice since no source of solid manganese melt stock could be found.

The thorium content measured by GDMS of the iridium scrap melted with manganese in the alumina crucible was 0.21 ppm. The two acid treatments described above resulted in analyzed thorium values of 0.13 and $0.22 \mathrm{ppm}$ respectively. The material contained large amounts of carbon from the reaction with the graphite susceptor and also silicon, chlorine, molybdenum, and tungsten.

The thorium contents measured by GDMS for the iridium scrap melted with manganese in a zirconia crucible were 0.05 and $0.18 \mathrm{ppm}$ respectively for the iridium melted with and without the graphite susceptor. The pure manganese melted in the zirconia crucible showed $<0.01 \mathrm{ppm}$ Th. This indicates little if any pickup of thorium from the zirconia crucible. A thorium content of $<1 \mathrm{ppm}$ is considered very acceptable.

A method of removal of thorium from iridium scrap has been demonstrated on a practical scale. The method is to melt the scrap with manganese metal to achieve an iridium content of about 15 to $30 \%$. It is best to use solid manganese melt stock so that the material may be air induction melted without the use of a susceptor. An argon cover gas is adequate. In the absence of a commercial source for solid manganese melt stock, the melt stock may be prepared by induction melting of manganese flake material using a graphite susceptor and not heating the melt much above the melting point of manganese. Measured thorium contents in the melted scrap are $0.2 \mathrm{ppm}$ or less. This compares with an anticipated value of about $10 \mathrm{ppm}$ that would be expected solely by dilution of the scrap material with manganese. The explanation of this is that the melting results in oxidation of the thorium, which then floats to the oxide slag on top of the melt. Radiation survey of the slag material failed to detect any measurable radiation.

The thorium levels after treatment are very acceptable for refining. The quoted cost for refining this material is $\$ 45$ per troy oz and $\$ 50$ per troy oz (\$1450/kg and $\$ 1600$ per $\mathrm{kg}$ ) for material with $60 \%$ iridium content and $15-20 \%$ iridium content respectively. The differential in the cost does not justify any effort to increase the iridium content prior to sending the scrap for refining. The acid treatments included in this investigation would be more expensive to perform than would be any savings on the commercial refining cost. The cost of the thorium removal at Oak Ridge National Laboratory by melting is estimated at about $\$ 500$ to $\$ 1000$ per $\mathrm{kg}$ of iridium treated. While these costs would be quite acceptable when compared to the historical price of iridium powder of $\$ 10,000$ per $\mathrm{kg}$, there is no large benefit currently to refining iridium when the current market price is about $\$ 3000$ per $\mathrm{kg}$. 


\subsection{IRIDIUM ALLOY BLANK PRODUCTION FOR NASA}

The goals for this activity are to produce flight-quality blanks and foil under full configuration control. During FY 2003 a total of 99 blanks with approved data packages were produced from the GR4 extrusion. The G5 ingot was produced from qualified G-batch powder and powder processing and electron-beam melting was begun for G6 ingot.

\subsubsection{Production of Blanks from GR4 Ingot}

The GR4 extrusion was cut to produce 17 rolling billets. These were rolled to produce 17 sheets in accordance with procedure MET-MatP-SOP-101. The sheets were machined to produce 102 blanks. A total of 100 blanks passed dimensional inspection and the two rejected blanks were submitted for weldability testing for information only. Sampling and cleaning was performed in accordance with procedure MET-MatP-SOP-102. All of the samples passed chemical analysis and metallographic evaluations. A total of 81 prime blanks were produced. An additional 18 blanks were reworked by sanding to remove visual indications of inclusions. The one remaining blank was used for tensile impact test specimens. Data packages were prepared and the blanks were placed in storage. The data packages were approved on April 1, May 8, and June 6, 2003 for totals of 29, 35, and 35 blanks respectively.

Tensile impact testing of material from the GR4 ingot for information purposes was completed. Tensile specimens from blank GR4-12-1 showed elongations of $20.8 \%$ and $22.2 \%$ as compared to a minimum requirement of $13.5 \%$. The material is tested at 980/C and 200 feet/sec following heat treatment at 1500/C for 19 hours.

\subsubsection{Processing of G5 Ingot for the Production of Blanks}

The G5 ingot was processed from qualified G-batch iridium powder. A total of six blends of iridium powder were prepared from $17.5 \mathrm{~kg}$ of powder. The powder was blended and compacted in accordance with procedure MET-MatP-SOP-72. The compacts were sintered in the newly qualified hydrogen furnace. The compacts were outgassed in the AVS vacuum furnace. Electron beam melting of the compacts was performed in accordance with procedure MET-MatP-SOP-82. Alloying of the electron-beam melted buttons and drop casting of electrode segments for the G5 ingot was performed in accordance with procedure MET-MatP-SOP-98. The nine electrode segments were electron beam welded in accordance with procedure MET-WB-SOP-31. The electrode was vacuum-arc remelted to produce the G5 ingot in accordance with procedure MET-MatP-SOP-99. The ingot was placed in a mating molybdenum can and extruded in accordance with procedure MET-MatP-SOP-100.

\subsubsection{Processing of G6 Ingot for the Production of Blanks}

The G6 ingot is being processed from $17.5 \mathrm{~kg}$ of qualified G-batch iridium powder. A total of six blends of iridium powder were prepared in accordance with MET-MatP-SOP-72, and identified as G-25 through G-30. The first three batch blends have been blended with tungsten, compacted, hydrogen sintered, vacuum outgassed, and electron beam melted to produce 15 buttons of Ir- $0.3 \% \mathrm{~W}$ alloy. The fourth batch blend has been processed through vacuum outgassing. A fifth batch (G-29) has been blended and weighed.

\subsubsection{Purchase of Iridium Powder}

A purchase order for 2000 troy oz. (about $62 \mathrm{~kg}$ ) of iridium powder was placed at a cost of $\$ 85$ per troy oz. (This near historically low cost for iridium made the refining of scrap iridium powder financially unattractive.) The powder was received in August in 10 jars representing 7 different lots from three producers. The powder was blended and sampled in accordance with procedure MET-Matp-SOP-72. Analysis by glow discharge mass spectrographic (GDMS) results showed that two of the lots do not meet the specification. One lot of $12 \mathrm{~kg}$ exceeds the specified limit for $\mathrm{Na}$ and one lot of $6 \mathrm{~kg}$ exceeds the limit for silicon. A nonconformance report was issued and the material is being returned to the vendor for replacement. In the temporary absence of approved carbon analysis equipment, samples were sent for carbon analysis, for information only, on a best effort basis by an outside vendor. These results indicate that the powder lots should meet the specification requirements for carbon in iridium powder.

\subsection{CLAD VENT SET PRODUCTION}




\subsubsection{Clad Vent Sets for DOE Maintenance Production}

The goal of this activity was to maintain Clad Vent Set (CVS) production capability by producing and shipping 10 fight quality (FQ) CVS to Los Alamos National Laboratory (LANL) by May 2003. Ten matched assemblies were shipped and received at LANL in late May 2003.

Studies were conducted to provide information for disposition of the 24 flight quality matched assemblies at LANL and the 10 vent cup assemblies at ORNL with potential tantalum contamination (from using the wrong tooling [tantalum instead of tungsten] for the frit vent assembly laser welding operation). Two frit vent-to-cup welds (TC39 and TC78) and a frit vent assembly (9752-test-0057) were examined by secondary ion mass spectrometry (SIMS), X-ray photoelectron spectrometry (XPS), and Auger electron spectrometry (AES). Flight quality status of the affected hardware was maintained by showing (using SIMS) that the level of tantalum did not exceed $100 \mathrm{wppm}$ on the surface nor 50 wppm in the bulk (by analyzing cross-sections in the vicinity of tantalum surface deposits) of the welds. Nonconformance report NCR-CVS-035 documented these results. It was accepted by the Radioisotope Power Systems community on January 29, 2003.

\subsubsection{Clad Vent Sets for NASA Production}

The goal of this activity was to produce and ship 34 FQ CVS to LANL in FY03 for the National Aeronautics and Space Administration (NASA) Pluto/New Horizons mission. Thirty four FQ matched assemblies were shipped and received at LANL in late September 2003.

Shield cup assembly (SCA) welding difficulties were encountered late in the fiscal year from an erratic electron beam deflection phenomenon. Numerous evaluations were performed. The electron gun filament (cathode) was replaced and the grid cup was examined. The anode plate and the column were cleaned. The alignment, focusing, and deflection coils were checked for electrical integrity. The optical viewer mirror was re-aligned and set. One identified problem was a charge build-up on the weld chamber viewing window (and uncontrolled discharge) exacerbated at higher vacuum levels. This was eliminated through light deposition of welding vapors on the viewing window and/or covering the window by raising the retractable shield plate before welding which dissipated any charge collection to ground.

The remaining erratic beam deflection appeared to be caused by magnetic interference either directly from the permanent magnets in the DC motor used to rotate the cups during welding or by magnetic coupling of the magnetic field with the pins and screws in the weld shield tab-to-cup tooling (T2E800505A008, Rev. A). Covering the motor with a carbon steel cylinder closed at one end tended to reduce or eliminate the interference depending on the proximity of the fixture position to the motor. Also degaussing the tooling (readings of 10 to 12 gauss against the tooling were reduced to 1 2 gauss) seemed to significantly reduce or even eliminate the interference as well. This suggested that the primary beam deflection was from magnetization of components (springs, screws, and/or pins) in the weld shield tab-to-cup tooling.

Stainless steel screws and pins certified to be austenitic were procured with the hopes they would have a low enough ferrite/martensite content so that they would not be or not become magnetized in the SCA tooling. The new screws and pins were checked with a hand-held gaussmeter (model EMUD2K by Electro-Matic Products Co. - Chicago, IL). The screws did not show notable residual magnetism (maximum 2 gauss) so they replaced the existing screws in the weld shield tab-to-cup tooling. The pins were somewhat magnetic (4 to 6 gauss) so they were not used. Since the degaussing of the tooling and replacement of the austenitic screws, beam deflection has not been a problem. The weld shield tab-tocup welding operation will be monitored closely and the tooling will be degaussed at the first sign of beam deflection problems.

\subsubsection{RSG55 Clad Vent Set Production}

The goal of this activity was to make preparations to produce long cups (17.58/17.66 mm [0.6921/0.6953"]) for the Radioisotope Stirling Generator 55 Watt Program (70 Watt Isotope Heat Source). This was completed with the submission of a Special Instruction Deviation Request, SIDR-CVS-005, to the ORNL RSG55 Configuration Control Board in late October 2003. 


\subsubsection{Single-Draw Forming Process Evaluation and Development}

Single-draw forming of standard blank assemblies requires a deep-draw reduction of $57 \%$. A standard $2^{\text {nd }}$-form punch and blankholder were modified to increase the stroke and ensure stripping of the cup from the punch. The usual preheats of $925^{\circ} \mathrm{C} / 10$ min for the blank assemblies and $250^{\circ} \mathrm{C}$ for the punch and die were used for most of the single-draw evaluation. Forming of cup TC112 using the standard blankholder spring force of $580 \mathrm{psi}$ at the start and building to 1350 psi showed that die lubrication with a standard grafoil washer (2.4" outer diameter and 1" inner diameter) alone was insufficient because of partial tearing of the cup bottom. For all subsequent cups the die was lubricated by "painting" on Fiske 604 lubricant and placing a 0.010" thick washer (2.4" outer diameter and 0.5" inner diameter) in the die counterbore.

The following single-draw process parameters were evaluated: (1) blank preheat temperatures from $800^{\circ} \mathrm{C}$ to $1000^{\circ} \mathrm{C}$; (2) blankholder spring loads of $360 \mathrm{initial} / 840$ final pounds, $560 \mathrm{initial} / 1300$ final pounds, and no load; (3) blankholder designs using a $3.3 \mathrm{~mm}(0.130 ")$ wide ring with a contact surface area of $\left.4 \mathrm{~cm}^{2}\left[0.62 \mathrm{in}^{2}\right]\right)$ and a $45^{\circ}$ taper versus a 14.6 $\mathrm{mm}$ (0.575") wide flat ring with a contact surface area of $21 \mathrm{~cm}^{2}$ [3.3 $\left.\mathrm{in}^{2}\right]$ ); (4) lubrication versus no lubrication of the blankholder; and (5) punch preheat temperature of $250^{\circ} \mathrm{C}$ versus no preheat. Conclusions reached after forming a series of 10 scrap cups were:

1) use of a blankholder reduced wrinkling,

2) sufficient blankholder force was achieved with springs,

3) a blankholder force of 900 to 2100 psi applied without lubricating the blankholder was too severe - cup bottom punched out of cup TC124,

4) a reduced blankholder force of 100 to 250 psi applied with the wide flat ring design (lubricated) reduced the wrinkling in the stainless steel waster sheets, however, wrinkling was still too excessive in the iridium cup,

5) increasing the blank assembly preheat temperature to $1015^{\circ} \mathrm{C}$ with the 100 to $250 \mathrm{psi}$ blankholder force applied with the wide flat ring design did not appreciably reduce wrinkling,

6) an increased blankholder force of 170 to $390 \mathrm{psi}$ applied with the wide flat ring design (lubricated) reduced the wrinkling sufficiently in the iridium cup,

7) the $57 \%$ drawing reduction can be done in a single draw with minimal wrinkling and sufficient cup height, however, the reduction was too severe to maintain the $0.55 \mathrm{~mm}$ minimum wall requirement near the cup radius,

8) wall thinning near the cup radius was not reduced through the use of a cold punch (to increase the yield strength of the material in the critical radius region), and

9) reducing the blank assembly preheat temperature did not increase the wall thickness in the radius region.

Longer shipping sleeves and containers are required to ship the longer matched assemblies. The high density polyethylene rods for making the shipping sleeves and the new polypropylene containers were received along with certification documentation. These materials were evaluated by scanning electron microscopy and energy dispersive spectroscopy. They were found to be acceptable for use. One hundred long shipping sleeves will be fabricated.

Initially, it was hoped that during long cup production those cups not meeting the extended length requirement could be diverted for regular CVS production (with a length requirement of 15.04/15.12 mm [0.5921/0.5953"]) if all other attributes were acceptable. The single-draw forming process yields cups with sufficient sound length, however, this additional length is at the expense of the wall thickness in the cup radius. Single-draw cups do not meet the standard cup minimum wall thickness requirement of $0.55 \mathrm{~mm}$. The requirement has been relaxed to a minimum of $0.48 \mathrm{~mm}$ in the radius which means cups originally intended to be long can not be diverted to make standard cups.

Five long cups, formed using the single-draw process, were fabricated to completion using non-FQ blanks. Shield cup TC5110 had a small diameter and a thin spot in the weld zone while shield cup TC5112 was out-of-round. The cause of these problems is attributed to the fact that these two cups were formed with the end of the punch approximately 3/8" below the blankholder face versus the other three cups being formed with the end of the punch flush with the blankholder face. Two each shield cup assemblies, vent cup assemblies, and matched assemblies were successfully produced.

\subsection{IRIDIUM POWDER AND INVENTORY MANAGEMENT}

The purpose of this work is to manage an iridium inventory for all heat source contractors with emphasis on the 
significant quantities of iridium located at Los Alamos National Laboratory and Oak Ridge National Laboratory and to maintain a no-change iridium inventory through an annual write-off of inventory and processing losses.

\subsubsection{Iridium Demand and Supply Schedule}

The annual update of the iridium demand and supply schedule is summarized in Table 2. This schedule, prepared for contingent planning purposes, presents a strategy to assess the availability of iridium for all development and production activities by projecting future demands. An adequate inventory needs to be maintained to meet the needs of the Pluto/New Horizons, MMRTG, and Stirling programs. Table 2 indicates that enough iridium will be available for these and for potential follow-on missions.

The first part of the table shows the estimated production demand factors for flight-quality (FQ) blanks and foil. The schedule of produced blanks and foil represents the quantity and timing for delivery or storage at Oak Ridge National Laboratory (ORNL). The ingots from new material represent the quantity produced from new iridium powder to make either blanks or foil. These ingots must be produced on a timely basis to meet the lead-time requirement to produce and deliver or store the blanks and foil.

The production of the FQ blanks and foil produces recyclable iridium material that can be placed back into the production process at ORNL. A greater economic benefit is realized by using recycled material, since the need to purchase powder from an outside vendor is reduced.

Refinable iridium scrap is also generated from the production of FQ blanks, non-FQ blanks, and foil. This scrap is sent to a commercial refinery when a sufficient accumulation occurs at ORNL, funding is available for the refining, and it makes economic sense based on a comparison of refining costs to that of new material.

Process losses of iridium occur during the working of the material at ORNL and Los Alamos National Laboratory. Losses also occur during the refining process. These inventory losses are written-off annually.

A iridium powder purchase was completed in FY 2003 as shown in the supply strategy portion of the table. The available recycle material and scrap has been considered to have been already recycled before calculating how much powder needs to be purchased.

The information in the table can be summarized as follows: With the completion of the iridium powder purchase contract in FY 2003, and a refining operation and additional purchase in FY 2005, there will be an adequate supply of iridium powder to produce the hardware for the three upcoming missions and $75 \mathrm{~kg}$ will remain at the beginning of FY 2007. 
Table 2. Demand and Supply Schedule Shows Factors and Provides Strategy to

Ensure an Adequate Supply of Iridium Powder for Follow-On Missions

After Pluto/New Horizons, MMRTG, and Stirling

\begin{tabular}{lcccc} 
& \multicolumn{5}{c}{ U. S. Government fiscal years } \\
\cline { 2 - 5 } \multicolumn{1}{c}{ Factors and strategy } & FY 2003 & FY 2004 & FY 2005 & FY 2006 \\
\hline & Production-demand factors & & \\
Produced blanks & 102 & 270 & 250 & 130 \\
Ingots from new material & 1 & 2 & 2 & 1 \\
Ingots from recyclable material & 0 & 1 & 1 & 1 \\
Produced foil (m $\left.{ }^{2}\right)$ & 0 & 0.4 & 0.4 & 0.3 \\
& Refining and process losses (kg) & & \\
Refining loss & 0 & 0 & 4.0 & 0 \\
Processing losses & 3.6 & 4.0 & 4.0 & 4.0 \\
& Supply strategy (kg) & & & \\
Beginning balance of powder & 52 & 95 & 59 & 93 \\
Receipt of refined powder & 0 & 0 & 40 & 0 \\
Receipt of purchased powder & 62 & 0 & 30 & 0 \\
\hline
\end{tabular}

$\overline{{ }^{1} \text { Fiscal year } 2007}$ beginning balance of powder is estimated to be $75 \mathrm{~kg}$.

\subsubsection{Annual Write-off}

The annual fiscal year 2003 write-off of iridium inventory was completed in June. A total of $5.4 \mathrm{~kg}$ of iridium was written off as a normal operating loss. The write-off appropriately reduced the non-fund iridium inventory. This 5.4 $\mathrm{kg}$ loss was considered a normal operating loss compared to the history of iridium losses during the past several years.

\subsubsection{Iridium Accountability Reviews}

A review at ORNL was conduced in May. The purpose of this review was to evaluate the accountability, physical inventory, and security of iridium at ORNL. It was concluded that the accountability, physical inventory, and security for the iridium was in place and operating in a proper manner. Two recommendations were proposed to enhance the present accountability and physical inventory system .

A review at LANL was conduced in July. The purpose of this review was to evaluate the accountability, physical inventory, and security of iridium at LANL. It was concluded that the accountability, physical inventory, and security for the iridium was in place and operating in a proper manner. One recommendation was proposed to enhance the present accountability and physical inventory system. 


\subsubsection{Report of Method for Removal of Thorium from Iridium Scrap}

A report on thorium removal from scrap iridium was completed and issued in June. Results in this report indicate that thorium removal from scrap iridium is not economical at this time. Therefore, a decision was made to purchase $62 \mathrm{~kg}$ of fresh iridium powder to cover production needs over the next several years.

\subsubsection{Shipment of Iridium}

The shipment of ten clad vent sets departed ORNL on May 21 and arrived at LANL on May 22. The security seals on the shipping container were intact upon arriving at LANL. U. S. Department of Energy Transfer Voucher No. 100-OR4AL1-113 dated June 11, 2003 was issued to properly account for this shipment.

The shipment of thirty-four clad vent sets departed ORNL on September 29 and arrived at LANL on September 30. The security seals on the shipping container were intact upon arriving at LANL. U. S. Department of Energy Transfer Voucher No. 100-OR4-AL1-113 dated September 25, 2003 was issued to properly account for this shipment.

\subsubsection{Report of Expended Precious Metals}

LANL personnel processed Report of Expended Precious Metals (Form 249-R) Number 200631 dated September 11, 2003 to write-off seven cut-open clads. These cut-open clads do not have any remaining useful life. DOE transfer voucher 309-AL1-OR4-014 dated September 25, 2003 was issued to transfer the 887 gram write off to ORNL. This LANL inventory loss will be written off the RPS iridium inventory on the annual fiscal year 2004 write-off. 


\section{ALLOY CHARACTERIZATION}

\subsection{EFFECTS OF AGING FOR UP TO FOUR MONTHS AT 500-700/C ON THE TENSILE PROPERTIES OF MO-41\%RE}

Alkali Metal Thermal-to-Electric Conversion (AMTEC) systems have the potential of producing electric power with higher conversion efficiency than the thermoelectric systems traditionally employed on board NASA deep space satellites. The primary construction material being considered for the AMTEC cell is arc-melted Mo-41\%Re (all compositions in wt.\% unless noted otherwise). ${ }^{1}$ This alloy was chosen because of its good ductility, strength, weldability, and compatibility with liquid and vapor sodium. ${ }^{2}$ Also, its rhenium concentration is low enough to minimize, if not avoid altogether, the formation of the brittle $\mathrm{F}$ phase. ${ }^{3}$ The solubility of rhenium in molybdenum is $\sim 39.5 \%$ at $750 / C$, which increases (decreases) at higher (lower) temperatures. When the solubility limit is exceeded, two rhenium-rich second phases can precipitate out, namely the $\mathrm{F}$ and $\mathrm{P}$ phases at temperatures above and below $\sim 1125 /$ C, respectively.

During its service life of up to 15 years, the AMTEC cell is expected to experience operating temperatures of 350 to 900/C. ${ }^{1}$ The $\mathrm{F}$ phase is stable only above $\sim 1125 / \mathrm{C}$, where nearly $44 \%$ Re is soluble in molybdenum; so it is unlikely that any $\mathrm{F}$ will precipitate out in the Mo-41Re alloy during service. However, the situation with the $\mathrm{P}$ phase is somewhat different. At the upper end of the operating temperature range (850-900/C), the phase diagram ${ }^{3}$ predicts that virtually all the rhenium in the Mo-41\%Re alloy will be in solution. At lower temperatures, however, some of the rhenium will come out of solution and form the $P$ phase since more of the $P$ phase is in thermodynamic equilibrium with the $\mathrm{Mo}(\mathrm{Re})$ solid solution at lower temperatures. ${ }^{3}$ How much precipitation occurs will depend on the kinetics of P-phase formation, which are expected to be extremely slow at low temperatures but for which no detailed data exist. Therefore, it was considered prudent to evaluate the kinetics of P-phase formation in Mo- $41 \%$ Re and determine what effect, if any, aging at intermediate temperatures has on its mechanical properties. This report summarizes our preliminary results on the effects of aging (for times up to 4 months) on the tensile properties measured at conventional strain rates.

Sheet material made from the MR-1 ingot, nominal composition Mo-41\%Re, was received in the fully recrystallized condition (recrystallization temperature, 1200/C) with a grain size of approximately $40: \mathrm{m}$. Details of the various processing steps needed to produce sheet from starting powder materials are given elsewhere. ${ }^{1,2,4}$ Tensile specimens with a gage section of $0.6 \times 2.5 \times 12.7 \mathrm{~mm}$ were machined from the as-received sheet, sealed in quartz capsules that were evacuated (to $\sim 5 \times 10^{-6}$ torr $=\sim 0.07 \mathrm{mPa}$ ) and backfilled with 1/3-1/2 atm $\left(\sim 3-5 \times 10^{4} \mathrm{~Pa}\right)$ of argon $(99.999 \%$ pure, batch

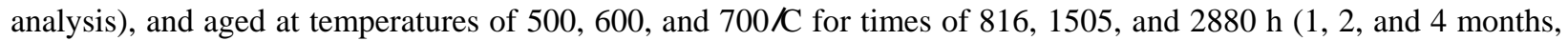
respectively). Grain growth is not expected at these annealing temperatures since they are much lower than the recrystallization temperature. Tensile tests were performed on a screw-driven Instron machine at temperatures of 20, 400 and $800 / \mathrm{C}$ at a strain rate of $10^{-3} \mathrm{~s}^{-1}$ in a vacuum better than $1.3 \mathrm{mPa}\left(10^{-5}\right.$ torr). Due to the shortage of material, only one tensile test was performed for each condition. The ductilities were determined by measuring the total specimen length before and after testing and assuming that all the elongation occurred in the gage section.

Figure 3.1 compares the as-received microstructure of the Mo-41\%Re alloy with its microstructure after annealing for 4 months at 700/C. As expected, there was no change in grain size after this anneal or after the longest anneal of 16 months $(\sim 11,500 \mathrm{~h})$, tensile impact results for which have been reported previously. ${ }^{7,8}$ Within the resolution limits of light microscopy, no second phase particles were found in any of the aged specimens. 

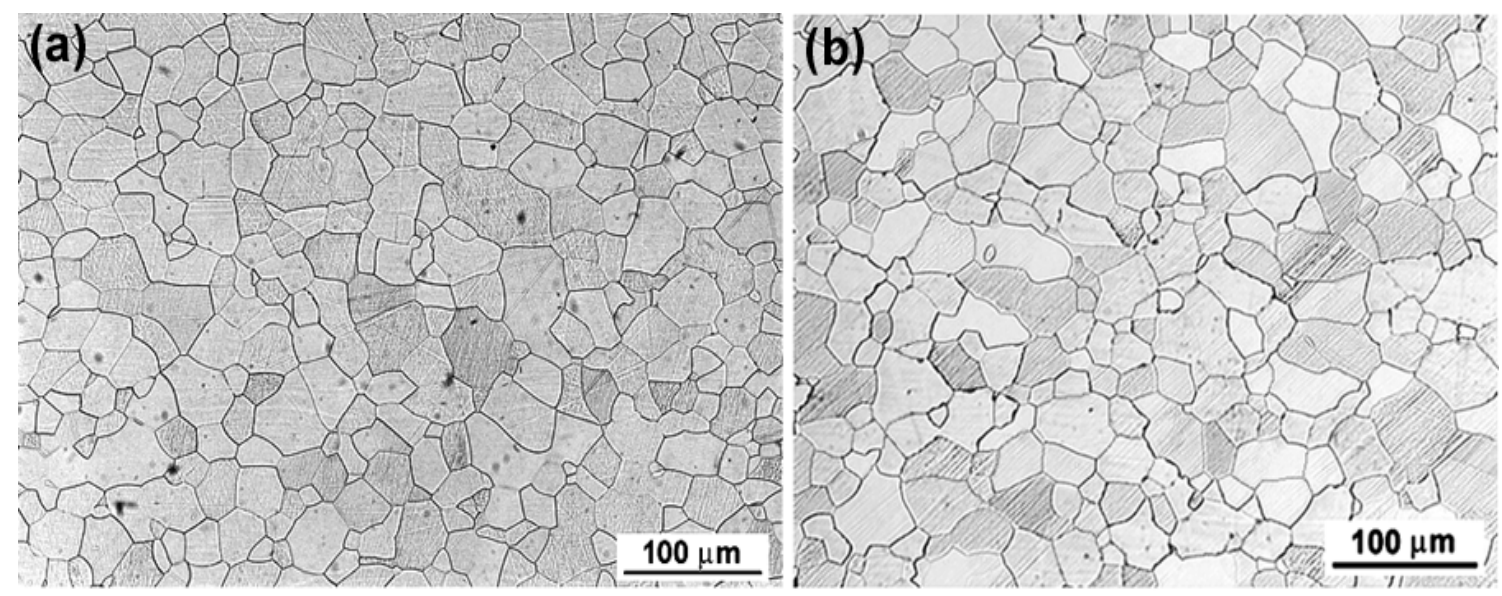

Fig. 3.1. Optical micrographs of Mo-41\%Re (a) as received and (b) after 4 months ( $2880 \mathrm{~h})$ at $700^{\circ} \mathrm{C}$.

The plots in Fig. 3.2 show the tensile properties as a function of aging time, aging temperature, and test temperature. The tensile tests were performed at 20,400, and 800/C. Most of the specimens were machined with their tensile axes parallel to the rolling direction. However, due to a shortage of material, two specimens had to be machined transverse to the rolling direction. Results from the transverse samples were consistent with those of the longitudinal samples. The results show that ductility remains high and roughly the same (28-36\%) for all aging and test conditions. Consistent with the high ductility measured in the tensile tests, fracture occurred in a ductile manner with considerable necking in the area of failure. The failure mode for a specimen aged at 700/C for approximately $2880 \mathrm{~h}$ and tensile tested at $800 / \mathrm{C}$ is illustrated by the fractographs shown in Fig. 3.3 and by optical micrographs shown in Fig. 4. These are representative of all the other tensile tests.

These results support the conclusions from tensile impact tests reported previously ${ }^{7,8}$ that either P-phase precipitation was not significant under these aging conditions, or the P-phase precipitates do not compromise elevated-temperature ductility. Additional tests are planned on specimens aged for longer times (up to 16 months).

In summary, Mo-41\%Re specimens were aged at temperatures of $500-700^{\circ} \mathrm{C}$ for times up to 4 months $(\sim 2880 \mathrm{~h})$ and then tensile tested at 20,400 , and $800^{\circ} \mathrm{C}$. Our results show that these aging treatments had no deleterious effect on the ductility. Tensile ductilities of $28-36 \%$ were measured for all specimens tested. 
Aging

temperature Yield strength
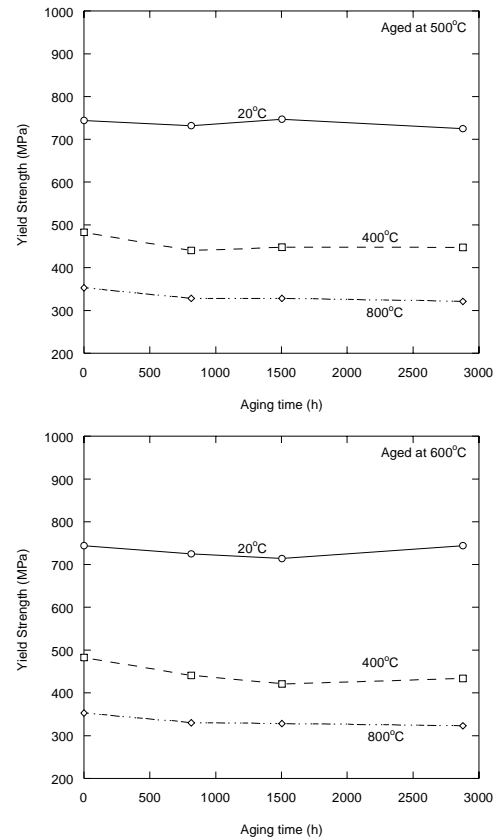

500/C

600/C

700/C

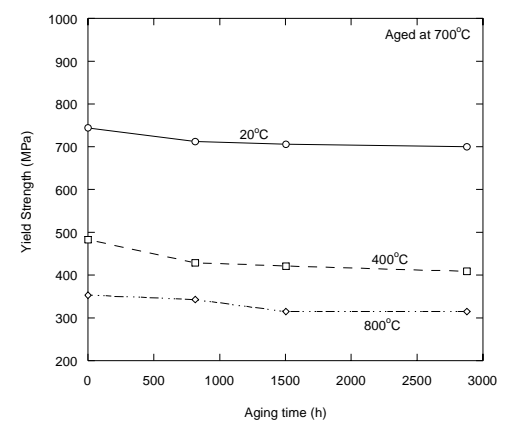

Tensile strength
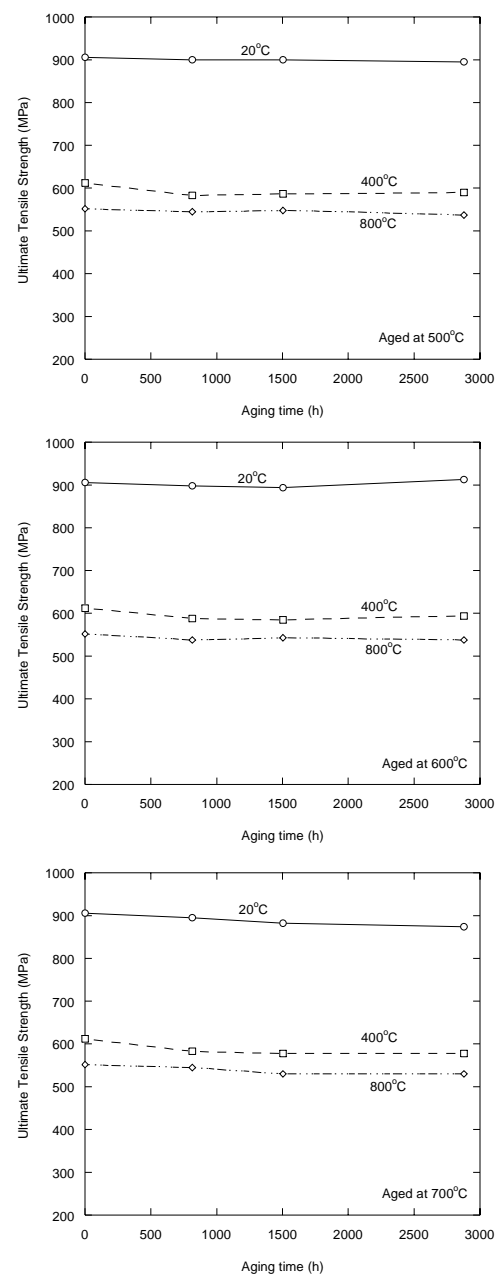

Elongation
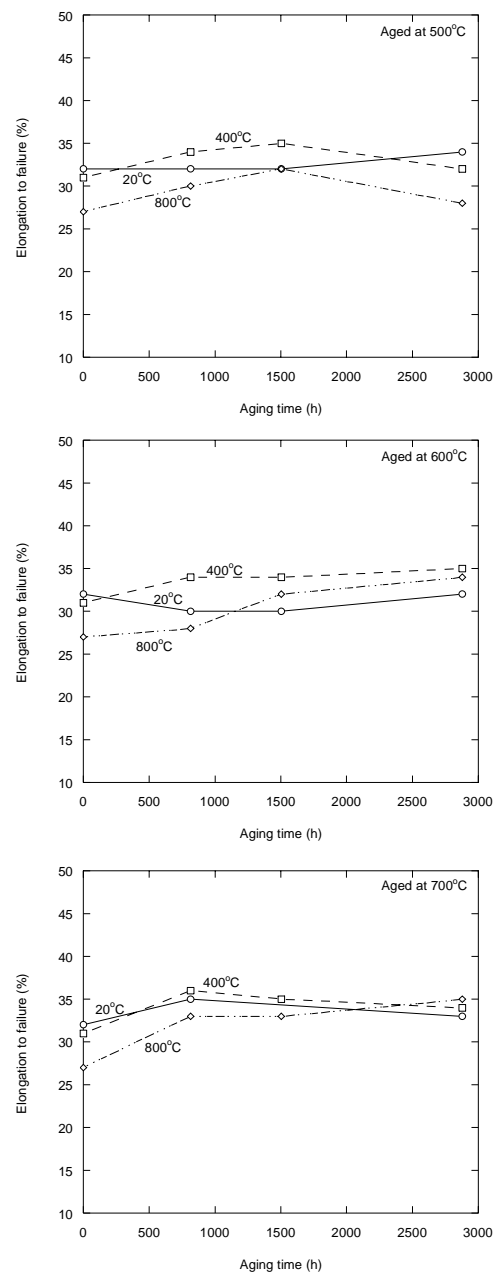

Fig. 3.2. Tensile properties of Mo-41\%Re as a function of aging time, aging temperature, and test temperature.

Fig. 3.3. Low (a) and high magnification (b) scanning electron fractographs showing the fracture mode of Mo-41\%Re tensile tested at 800/C after aging for $2880 \mathrm{~h}(\sim 4$ months) at 700/C.
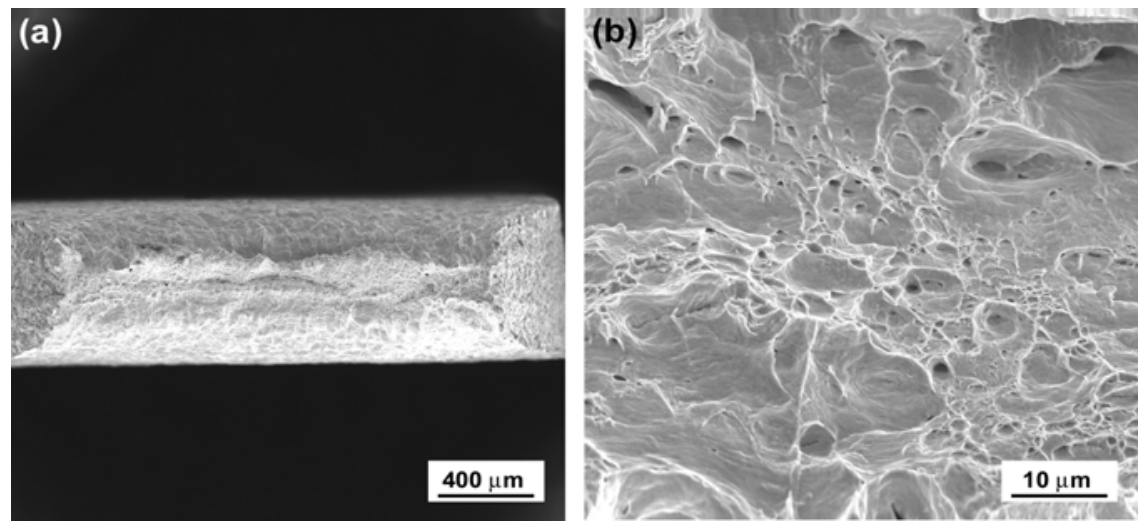
Fig. 3.4. Optical micrographs showing failure in a Mo-41\%Re tensile specimen tested at $800 / \mathrm{C}$ after aging for $2880 \mathrm{~h}$ ( 4 months) at 700/C.

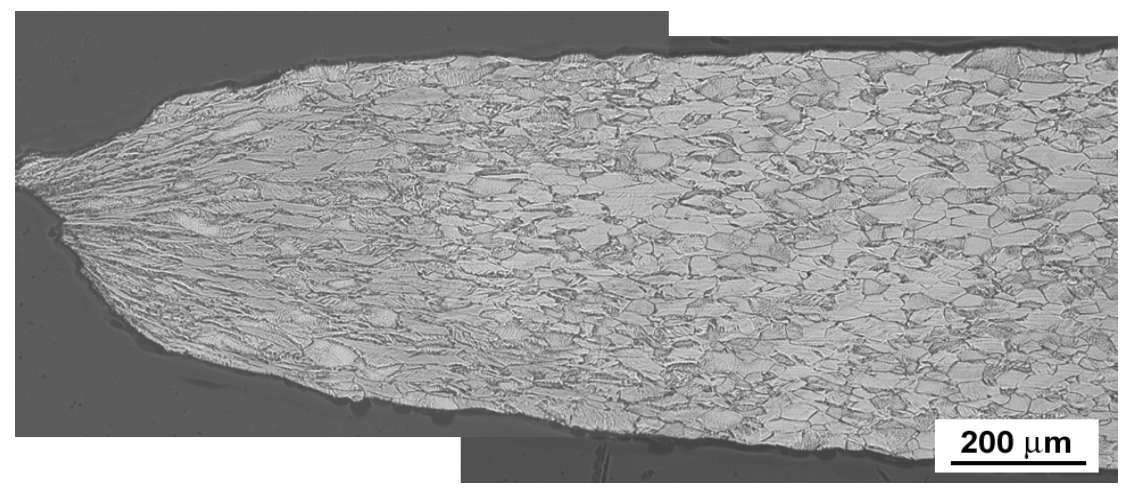

\section{References}

1. J. P. Moore, J. F. King, J. R. DiStefano, and E. K. Ohriner, in Proc. Space Technology and Applications International Forum (STAIF-2002), February 3-7, 2002, Albuquerque, NM, paper log\# 202/D10 (to be published).

2. J. F. King, J. R. DiStefano, J. P. Moore, and E. K. Ohriner, "Production and properties of Mo-41\%Re for AMTEC cell construction," attachment to Letter No. 0929-46-00, J. P. Moore to A. S. Mehner and L. C. Herrera, September 29, 2000.

3. Binary Alloy Phase Diagrams (editor-in-chief T. B. Massalski), American Society for Metals, Metals Park, Ohio (1986).

4. Semiannual Technical Progress Report of the Radioisotope Power System Materials Production and Technology Program Tasks for September 2000 through March 2001, ORNL/CF-01/24, May 8, 2001.

5. C. T. Liu, H. Inouye, and A. C. Schaffhauser, Metall. Trans. A12 (1981) 993.

6. C. G. McKamey, E. P. George, E. H. Lee, E. K. Ohriner, L. Heatherly, and J. W. Cohron, Scripta Mater. 42 (2000) 9.

7. E. P. George, C. G. McKamey, and E. H. Lee, "Effects of Aging Up to 4 Months at $500-700^{\circ} \mathrm{C}$ on the Impact Ductility of Mo-41\%Re,” attachment to letter, J. P. Moore to A. S. Mehner, Sept. 25, 2001.

8. C. G. McKamey, E. H. Lee, and E. P. George, "Effects of Aging Up to 16 Months at $500-700^{\circ} \mathrm{C}$ on the Impact Ductility of Mo-41\%Re,” attachment to letter, J. P. Moore to A. S. Mehner, Sept. 25, 2002. 


\subsection{COMPATIBILITY OF HAYNES ALLOY 25 WITH GRAPHITE}

Capsules made of the Haynes 25 alloy are to be used for fuel containment in the Advanced Long Term Battery Heat Source [1,2]. Prior to service, the surfaces of the Haynes 25 capsules are oxidized in air at 750/C for $72 \mathrm{~h}$ to increase their emissivity. In the generator, the capsules are set off from the surrounding graphite with a gap of approximately $0.030-0.035$ inch; that is, they do not come into direct physical contact with the graphite. The nominal composition of the gas in the generator is $\mathrm{Ar}-5 \% \mathrm{He}$. Pieces of zirconium are placed at various locations in the generator in close proximity to the Haynes 25 capsules to getter any oxygen that may be present in the generator environment. The nominal operating temperature experienced by the capsule is 675/C. Because limited information is available on the effects of exposure in such an environment on the mechanical properties, it was judged necessary to evaluate the compatibility of graphite with the Haynes 25 material.

If any carbon is to diffuse into the Haynes 25 alloy and form carbides, its transport to the outer surfaces of the capsules would have to be through the gas phase (e.g., as $\mathrm{CO}$ ) since there is no physical contact between the graphite and the capsules. In addition, once it reaches the outer surface, the carbon would have to dissociate into atomic carbon and then diffuse through the outer oxide layer to reach the underlying metal, or first reduce the outer oxide layer and then diffuse into the Haynes 25.

A large heat of Haynes 25 has been produced for use in the heat source and specimens of that heat were used in this study. The objective was to determine the effects of long-term exposure to graphite in a simulated generator environment on the mechanical properties of Haynes 25. Actual operating conditions were simulated as closely as was possible in a laboratory environment. After aging in this environment for long times, tensile properties were measured in order to determine whether such an exposure produced any embrittlement of the Haynes 25 alloy.

Haynes 25 sheet stock ( $3.5 \mathrm{~mm}$ thick) was received from Mound Laboratories in the recrystallized condition (Mound Labs, heat \# 1860-8-1391), having an ASTM grain size of $4(\sim 90: \mathrm{m})$. From this sheet, tensile specimens with a gage section of $0.6 \times 2.5 \times 12.7 \mathrm{~mm}$ were machined and their surfaces were ground to a 600 -grit finish. After cleaning in acetone, half of the specimens were oxidized in air for $72 \mathrm{~h}$ at 750/C to simulate the surface condition of the capsules in the generator. The remaining specimens were left unoxidized in order to investigate whether there were any effects of the oxide layer on graphite compatibility.

Figure 3.5 is a drawing of the graphite fixture that was used to hold the tensile specimens for the aging experiments. Figure 3.6 is a photograph of an actual graphite fixture. It was machined from DM302W grade graphite provided to us by Teledyne Energy Systems. Each fixture contained slots for 4 tensile specimens, as well as two wells to contain pieces of zirconium getter. After machining, the fixtures were shipped to Teledyne Energy Systems where they were out-gassed at 1093/C (2000/F) for a minimum of $6 \mathrm{~h}$ according to procedure PS-0200008. After the graphite fixtures were returned from Teledyne Energy Systems, two oxidized and two unoxidized specimens were placed in each fixture, one specimen in each of the four slots. There was a 0.035 inch clearance between the specimen surfaces and the surrounding graphite (except for the very ends of the grip sections of each specimen where they were in physical contact with the graphite). This arrangement was devised to simulate the operating condition in the generator where the capsules are set off from the graphite with a gap of this magnitude. Pieces of zirconium getter were placed in small crucibles machined out of Inconel Alloy 800 plate and inserted into the two wells in each fixture. Each well was connected by a small pathway to two specimen slots. The entire fixture/specimen assembly was placed in a 2.1-in.-diameter quartz tube that was evacuated, backfilled with an Ar-5\% He gas mixture at 500 torr pressure, and sealed. To provide baseline data for comparison, two oxidized and two unoxidized specimens were also sealed into each of four smaller quartz tubes without any graphite present. 
Fig. 3.5. Schematic drawing of graphite fixture for holding Haynes 25 tensile specimens during aging.
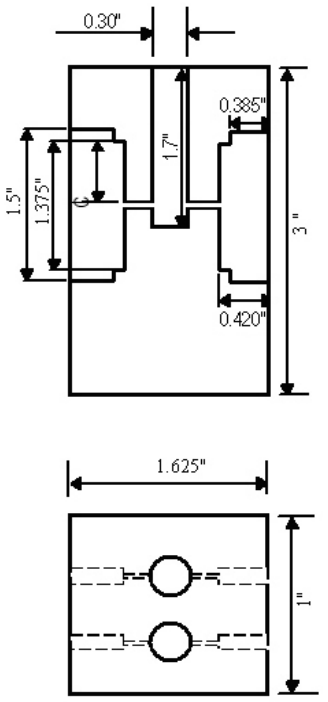

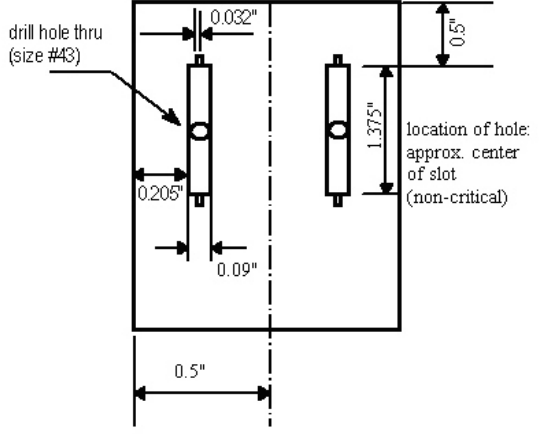

Drawing not to scale

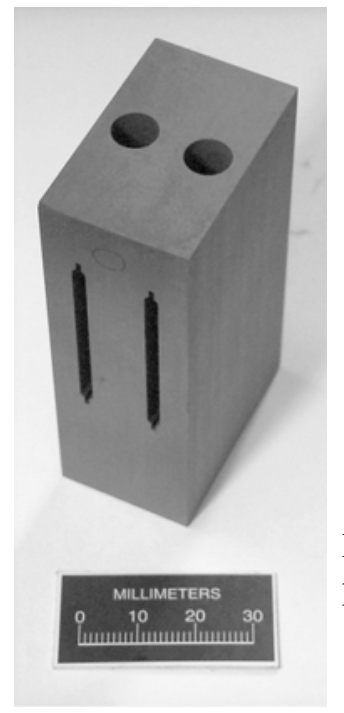

Fig. 3.6. Photograph of one of the graphite fixtures prior to loading with tensile specimens.

Figure 3.7 shows a drawing of the stainless steel fixture that was used to position and stabilize the specimens in the furnace hot-zone. The four quartz tubes containing graphite fixtures were inserted through holes in the top plate and allowed to rest on the bottom plate. In addition, the four quartz tubes without graphite were placed through the smaller holes in the top plate and allowed to seat in small positioning holes on the bottom plate. Figure 3.8 shows the loaded fixture ready to be placed in the furnace. The loaded fixture was placed in a clam-shell electric furnace mounted vertically on creep frames and thermocouples were attached adjacent to the quartz capsules to monitor the temperature during the aging heat treatment. During this reporting period, aging was performed at 675/C for times of 2040 and $4560 \mathrm{~h}$. 
Fig. 3.7. Schematic drawing of stainless steel fixture for holding quartz capsules inside the aging furnace.
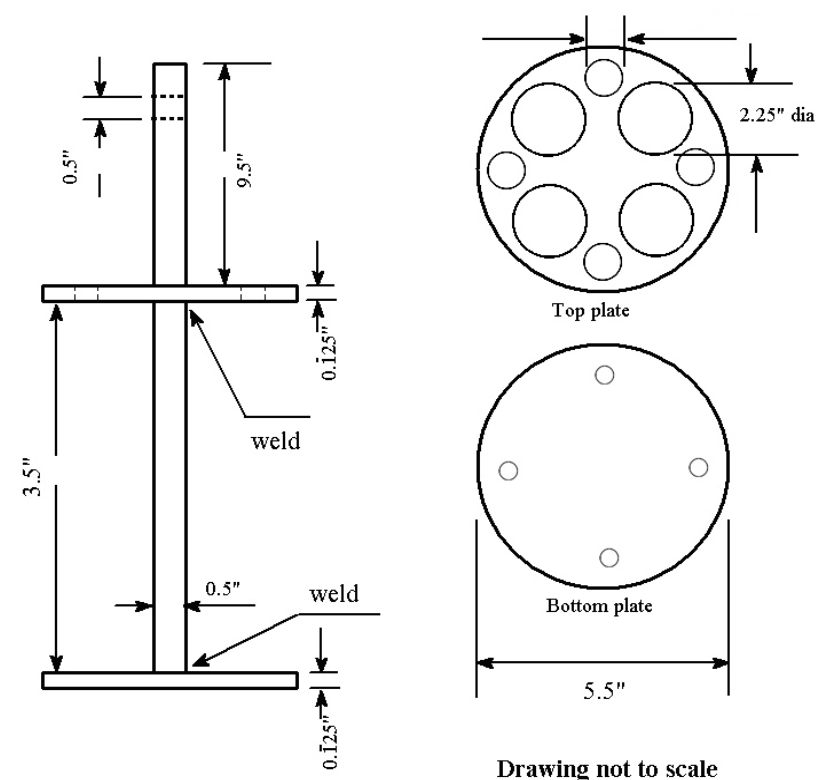

Drawing not to scale

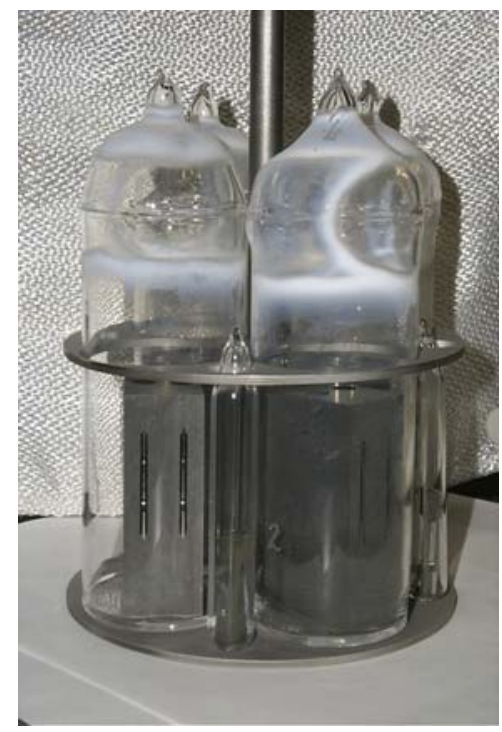

Fig. 3.8. Photograph of the loaded holding fixture ready for placement in the furnace.

Tensile tests were performed on the aged specimens using a screw-driven Instrn machine at a strain rate of approximately $3 \times 10^{-3} \mathrm{~s}^{-1}$ and at a temperature of 675/C. Duplicate specimens were tested for each aging condition, and elongation to fracture was used as a measure of embrittlement. Yield and ultimate tensile strength were also measured to determine whether there was any evidence of excess strengthening as a function of aging in graphite.

The tensile-tested specimens were examined by both light and scanning electron microscopy (including energy dispersive spectroscopy) to look for evidence of any carbide precipitation in the near-surface regions of the aged specimens. The fracture modes of the aged specimens were also studied to determine if there was any difference between those aged with and without graphite.

The complete test specimen matrix and the planned aging times are shown in Table 3.1. The actual aging times vary slightly from those proposed to allow for timely extraction of capsules to provide data for the ALTB quarterly review 
meetings. This report covers the first two sets of specimens that were aged for 2040 and $4560 \mathrm{~h}$.

Figure 3.9 shows the effect of aging on the strength and ductility of Haynes alloy 25 tensile tested in vacuum at $675^{\circ} \mathrm{C}$. The closed symbols represent the present data, while the open symbols represent data generated earlier by Swindeman [3] on larger tensile samples (gage size $3.4 \times 9.6 \times 56 \mathrm{~mm}$ ) tested at $650^{\circ} \mathrm{C}$. As is shown, the current data are comparable to the Swindeman data. For the aging times reported here, there appears to be no difference between those specimens

Table 3.1. Planned test matrix for aging treatments in graphite

\begin{tabular}{|c|c|c|c|c|c|}
\hline \multirow[b]{2}{*}{$\begin{array}{l}\text { Specimen } \\
\text { condition }\end{array}$} & \multicolumn{2}{|c|}{ No graphite } & \multicolumn{2}{|c|}{ With graphite } & \multirow{2}{*}{ Remarks } \\
\hline & $\begin{array}{c}\text { No. of } \\
\text { specimens }\end{array}$ & $\begin{array}{l}\text { Aging time } \\
\text { at } 675 / \mathrm{C}(\mathrm{h})\end{array}$ & $\begin{array}{c}\text { No. of } \\
\text { specimens }\end{array}$ & $\begin{array}{l}\text { Aging time } \\
\text { at 675/C (h) }\end{array}$ & \\
\hline Unoxidized & 2 & 0 & -- & -- & $\overline{\text { Completed }}$ \\
\hline Oxidized & 2 & 0 & -- & -- & Completed \\
\hline Unoxidized & 2 & 2500 & 2 & 2500 & Completed \\
\hline Oxidized & 2 & 2500 & 2 & 2500 & Completed \\
\hline Unoxidized & 2 & 5000 & 2 & 5000 & Completed \\
\hline Oxidized & 2 & 5000 & 2 & 5000 & Completed \\
\hline Unoxidized & 2 & 8000 & 2 & 8000 & $\overline{\text { Being aged }}$ \\
\hline Oxidized & 2 & 8000 & 2 & 8000 & Being aged \\
\hline Unoxidized & 2 & 12000 & 2 & 12000 & Being aged \\
\hline Oxidized & 2 & 12000 & 2 & 12000 & $\overline{\text { Being aged }}$ \\
\hline
\end{tabular}

(a)

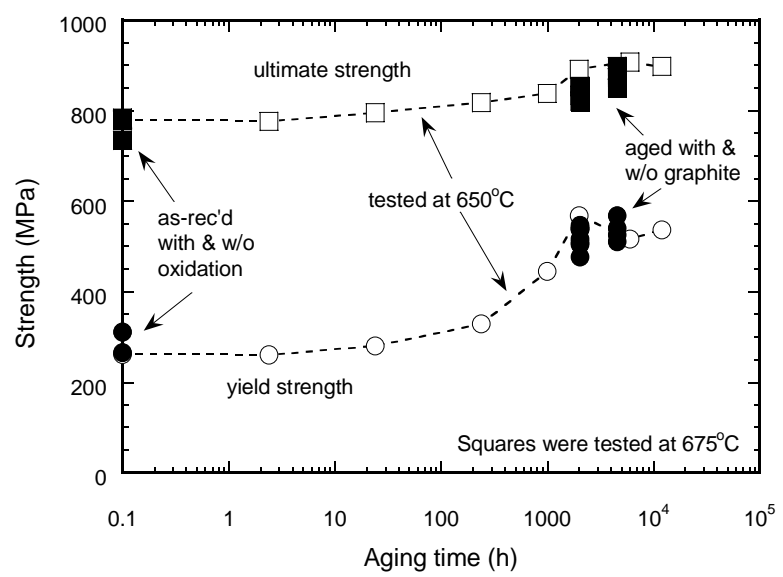

(b)

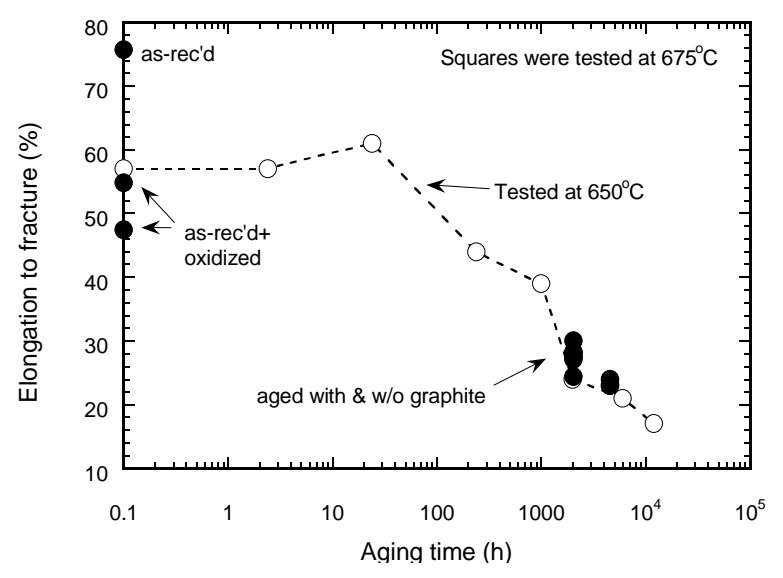

Fig. 3.9. Effects of oxidation and aging at $675^{\circ} \mathrm{C}$ with and without graphite on the (a) tensile strength and (b) ductility of Haynes 25. Data for tensile tests at $650^{\circ} \mathrm{C}$ were taken from Ref. 3 . 
aged in the presence of graphite and those without graphite, both when the graphite-aged specimens in the present study are compared to the Swindeman data and also when compared to specimens in the past that were aged without graphite [4,5]. In addition, the fracture modes (Fig. 3.10) were typical of Haynes alloy 25 [see Refs. 4,5], both for the as-received specimens and the aged specimens. Scanning electron microscopy and energy dispersive spectroscopy showed no evidence of carbide formation in the near-surface regions (Fig. 3.11). Only oxides formed during the preoxidation treatment and Co-W-containing precipitates typically associated with this alloy were identified.
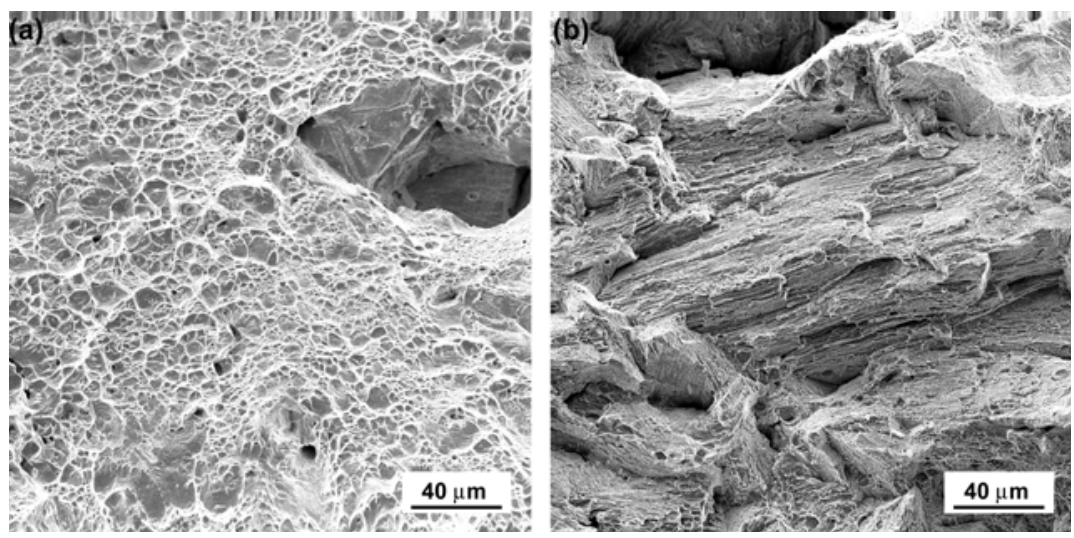

Fig. 3.10. Scanning electron images showing tensile fractures of Haynes alloy 25 tensile tested at 675/C: (a) as received, (b) aged for $2040 \mathrm{~h}$ at 675/C in the presence of graphite.
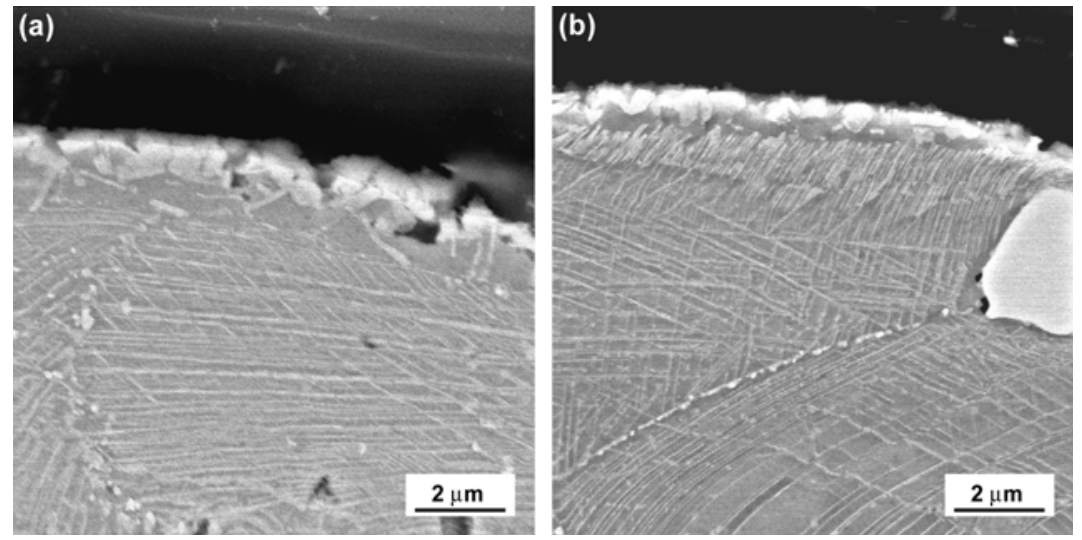

Fig. 3.11. Scanning electron images showing the surfaces of Haynes alloy 25 tensile specimens: (a) aged $4560 \mathrm{~h}$ without graphite and (b) aged $4560 \mathrm{~h}$ in the presence of graphite. Aging was performed at 675/C.

In summary, the purpose of this study was to evaluate the potential for graphite-induced embrittlement in the Haynes 25 during aging in simulated generator environments. During this reporting period, the anneals were conducted at $675^{\circ} \mathrm{C}$ for times of 0,2040 , and $4560 \mathrm{~h}$. Optical metallography, scanning electron microscopy, and energy dispersive spectroscopy were used to look for the presence of carbides. The results showed no embrittlement of the Haynes 25 material as a result of aging in graphite compared to specimens aged in vacuum. These tests are planned to continue into the next fiscal year, through approximately $12,000 \mathrm{~h}$.

\section{References}


1. J. Kovacic and M. F. McKittrick, "Preliminary Safety Test Plan for the Advanced Long Term Battery Heat Source,” Rev. 1, TBE-21501-040, Teledyne Brown Engineering Energy Systems, Hunt Valley, MD, October 1998.

2. R. W. Swindeman, "Review of the Mechanical Behavior of Haynes Alloy No. 25," Oak Ridge National Laboratory, July 15, 1998.

3. R. W. Swindeman, C. O. Stevens, and R. L. Martin, "Characterization of Haynes Alloy 25 Sheet Materials for the ALTB IHS Test Plan: Low Strain Rate Tensile Results,” letter report to DOE, 1999.

4. C. G. McKamey, E. H. Lee, J. L. Wright, and E. P. George, "Effect of Aging on Tensile Impact Ductility of Haynes Alloy 25,” attachment to letter, J. P. Moore to A. S. Mehner, June 29, 2001.

5. C. G. McKamey, R. W. Swindeman, E. H. Lee, J. L. Wright, and E. P. George, "Effect of Strain Rate and Aging on Mechanical Behavior of Haynes Alloy 25 Aged at $675^{\circ}$ C," attachment to letter, J. P. Moore to A. S. Mehner, Sept. 27, 2002. 


\subsection{TECHNICAL SUPPORT FOR THE IHS70 PROGRAM}

A new radioisotope power system (IHS70) is being developed that uses iridium cladded plutonia fuel enclosed within nested capsules of Ta-10W, molybdenum, and Haynes 230. The Ta-10W capsule is designed to retain helium pressure during long years of system service. The outer capsule is made of Haynes 230 to protect the inner capsules from oxidation. This task provides technical support for the IHS70 program by investigating the effects of oxygen on the mechanical properties of the Ta-10W alloy.

Round bar (button head) tensile specimens were machined from Ta-10W bar stock existing at ORNL with a gage length of approximately $0.5 \mathrm{in}$. and gage diameter of $0.1 \mathrm{in}$. The specimens were tensile tested in one of three conditions: asreceived, as-received plus annealed in vacuum $\left(4 \mathrm{~h} / 1427^{\circ} \mathrm{C}\right)$, or as-received plus annealed and oxidized. The oxidation treatment consisted of annealing at $1000^{\circ} \mathrm{C}$ in pure oxygen at $\mathrm{P}_{\mathrm{O} 2} \sim 9 \times 10^{-6}$ torr for various lengths of time followed by vacuum annealing at $1000^{\circ} \mathrm{C}$ for $8 \mathrm{~h}$ to homogenize the oxygen concentration. Tensile tests were performed on a screwdriven Instron machine at room temperature $\left(\sim 20^{\circ} \mathrm{C}\right)$ in air or vacuum [vacuum of approximately $0.07 \mathrm{mPa}\left(\sim 5 \times 10^{-6}\right.$ torr)] or at $760^{\circ} \mathrm{C}$ in vacuum. The strain rate was $10^{-3} \mathrm{~s}^{-1}$. The ductilities were characterized by determining the change in length (by measuring the total specimen length before and after testing and assuming that all the elongation occurred in the gage section) and the reduction in area at the fracture plane. After fracture, selected specimens were sent to Wah Chang (Albany, OR) for oxygen analysis. Optical metallography and scanning electron microscopy of the fracture surfaces were performed on selected specimens.

Table I shows the results of tensile tests conducted to date. There is no difference in strength or ductility between the as-received and annealed specimens when tested in air at room temperature or when tested in vacuum at $760^{\circ} \mathrm{C}$. A typical fracture mode is shown in Fig. 3.12 for specimen \#3 which failed with an elongation of $42.2 \%$. Fracture occurred by dimpled rupture and the specimen necked almost to a point. Of the oxidized specimens, only those containing less than approximately 500 ppm oxygen retained their room temperature properties. Larger amounts of oxygen resulted in severe embrittlement, with fracture occurring in a mixed mode along grain boundaries and cleavage planes (see Fig. 3.13).
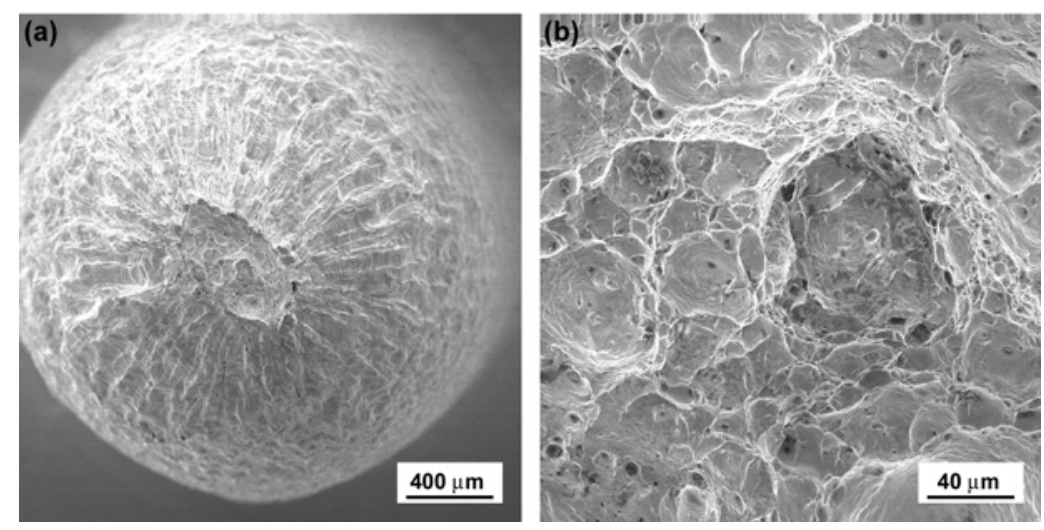

Fig. 3.12. Low (a) and high magnification (b) scanning electron fractographs of Ta-10W in the annealed condition, tensile tested at room temperature in air. 
Table I. Tensile Properties of Ta-10W

\begin{tabular}{|c|c|c|c|c|c|c|c|c|}
\hline $\begin{array}{c}\text { Specimen } \\
\#\end{array}$ & $\begin{array}{l}\text { Specimen } \\
\text { Condition }\end{array}$ & $\begin{array}{l}\text { Tensile test } \\
\text { temp. }\left({ }^{\circ} \mathrm{C}\right)\end{array}$ & $\begin{array}{c}\text { Test } \\
\text { environment }\end{array}$ & $\begin{array}{c}\text { YS } \\
(\mathrm{ksi})\end{array}$ & $\begin{array}{l}\text { UTS } \\
\text { (ksi) }\end{array}$ & $\begin{array}{c}\text { Elong. } \\
\text { (\%) }\end{array}$ & $\begin{array}{l}\text { RA } \\
(\%)\end{array}$ & $\begin{array}{c}\text { Calculated }^{\mathrm{c}} \\
\text { (analyzed) } \\
\text { oxygen (ppm) }\end{array}$ \\
\hline $\begin{array}{l}1 \\
5\end{array}$ & $\begin{array}{l}\text { as-rec’d } \\
\text { as-rec'd }\end{array}$ & $\begin{array}{l}\text { RT } \\
\text { RT }\end{array}$ & $\begin{array}{l}\text { air } \\
\text { air }\end{array}$ & $\begin{array}{l}66.8 \\
66.6\end{array}$ & $\begin{array}{l}83.5 \\
81.8\end{array}$ & $\begin{array}{l}35.9 \\
37.7\end{array}$ & $\begin{array}{l}78 \\
85\end{array}$ & $\begin{array}{l}-- \\
--\end{array}$ \\
\hline $\begin{array}{c}3 \\
9 \\
10\end{array}$ & $\begin{array}{l}\text { annealed } \\
\text { annealed } \\
\text { annealed }\end{array}$ & $\begin{array}{l}\text { RT } \\
\text { RT } \\
\text { RT }\end{array}$ & $\begin{array}{l}\text { air } \\
\text { air } \\
\text { air }\end{array}$ & $\begin{array}{l}66.9 \\
84.7 \\
67.7\end{array}$ & $\begin{array}{c}81.5 \\
102.3 \\
82.0\end{array}$ & $\begin{array}{l}42.2 \\
37.9 \\
40.2\end{array}$ & $\begin{array}{l}96 \\
24 \\
96\end{array}$ & $\begin{array}{l}-- \\
-- \\
--\end{array}$ \\
\hline $\begin{array}{c}2 \\
11\end{array}$ & $\begin{array}{l}\text { as-rec'd } \\
\text { as-rec'd }\end{array}$ & $\begin{array}{l}760 \\
760\end{array}$ & $\begin{array}{l}\text { vacuum } \\
\text { vacuum }\end{array}$ & $\begin{array}{l}23.6 \\
25.1\end{array}$ & $\begin{array}{l}41.1 \\
44.1\end{array}$ & $\begin{array}{l}33.0 \\
32.0\end{array}$ & $\begin{array}{l}94 \\
95\end{array}$ & $\begin{array}{l}-- \\
--\end{array}$ \\
\hline $\begin{array}{l}14 \\
15\end{array}$ & $\begin{array}{l}\text { annealed } \\
\text { annealed }\end{array}$ & $\begin{array}{l}760 \\
760\end{array}$ & $\begin{array}{l}\text { vacuum } \\
\text { vacuum }\end{array}$ & $\begin{array}{l}24.1 \\
26.4\end{array}$ & $\begin{array}{l}44.7 \\
48.0\end{array}$ & $\begin{array}{l}30.9 \\
32.4\end{array}$ & $\begin{array}{l}91 \\
92\end{array}$ & $\begin{array}{l}-- \\
--\end{array}$ \\
\hline $\begin{array}{l}1 \\
2\end{array}$ & $\begin{array}{l}\text { oxidized } \\
\text { oxidized }\end{array}$ & $\begin{array}{l}\mathrm{RT} \\
\mathrm{RT}\end{array}$ & $\begin{array}{l}\text { vacuum } \\
\text { vacuum }\end{array}$ & $\begin{array}{l}\mathrm{a} \\
\mathrm{a}\end{array}$ & $\begin{array}{l}20.9^{\mathrm{b}} \\
21.1^{\mathrm{b}}\end{array}$ & $\begin{array}{l}\sim 0 \\
\sim 0\end{array}$ & $\begin{array}{l}0 \\
0\end{array}$ & $\begin{array}{c}1403(1020) \\
1260(970)\end{array}$ \\
\hline $\begin{array}{l}3 \\
4\end{array}$ & $\begin{array}{l}\text { oxidized } \\
\text { oxidized }\end{array}$ & $\begin{array}{l}\text { RT } \\
\text { RT }\end{array}$ & $\begin{array}{l}\text { vacuum } \\
\text { vacuum }\end{array}$ & $\begin{array}{l}88.9 \\
96.8\end{array}$ & $\begin{array}{c}99.7 \\
106.8\end{array}$ & $\begin{array}{l}37.4 \\
38.1\end{array}$ & $\begin{array}{l}96 \\
92\end{array}$ & $\begin{array}{l}372(270) \\
516(410)\end{array}$ \\
\hline
\end{tabular}

a Specimen fractured before yielding.

b Fracture strength.

${ }^{\mathrm{c}}$ From weight gain after oxidation.

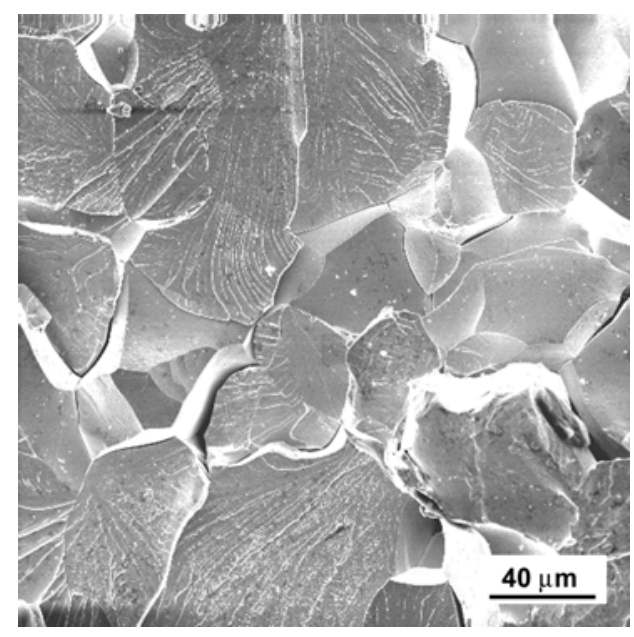

Fig. 3.13. Scanning electron fractograph of oxidized Ta-10W specimen \#2 (containing 1260 ppm oxygen), tensile tested at room temperature in vacuum. 


\subsection{PLUTONIUM PRODUCTION STUDIES}

There are two major subtasks that occurred during FY2003. The first subtask was a study undertaken to determine the effect of radiolysis of water during long-term storage of $\mathrm{NpO}_{2}$. Data from this task are critical in determining safe storage configurations for $\mathrm{NpO}_{2}$. The $\mathrm{NpO}_{2}$ is scheduled to be transferred from the Savannah River Site (SRS) in FY2005 and FY2006. In the second subtask, we continued post irradiation examination of (PIE) array targets. These tests focused on dissolving the plutonium produced during irradiation in the Idaho National Laboratory (INL) Advanced Test Reactor (ATR). Data from the array targets will serve as a baseline for developing the chemical processing flowsheet.

\subsection{EVALUATION OF THE RADIOLYTIC DECOMPOSITION OF MOISTURE SORBED ON NpO ${ }_{2}$}

The neptunium feedstock for the ${ }^{238} \mathrm{Pu}$ Production Program currently exists in a liquid nitrate solution in the SRS HCanyon. The solution will undergo chemical processing in a glove-box line known as HB-Line Phase II to remove impurities and convert to an oxide as depicted in Fig. 4.1. The neptunium solution will first undergo a feed adjustment to $6-8 \mathrm{M} \mathrm{HNO}_{3}$. The adjusted solution is then fed into anion exchange columns where the neptunium nitrate complex absorbs, allowing most metal impurities to pass through the column. Next, a decontamination wash is performed to remove residual impurities. Finally, a weak nitric-acid solution is passed through the column to elute the neptunium. Once the anion exchange process has been completed, the resulting neptunium solution is combined with oxalic acid, which forms an insoluble neptunium oxalic precipitant. This product is filtered and the neptunium oxalate is then calcined at $\sim 600^{\circ} \mathrm{C}$ to convert the oxalate to oxide.

The oxide will be packaged in a can-bag-can configuration for shipment (Fig. 4.1). The inner can, which contains up to $6 \mathrm{~kg} \mathrm{NpO}$, is a screw-top, food pack convenience can. Because no gasket or sealing compounds are used on the closure, this inner can will not be gas tight. The inner can is contained in a heat-sealed bag which has a HEPA filter installed in it. This arrangement will then be placed inside an outer can, which has a HEPA filter in its lid. Finally, the can-bag-can will then be placed inside a 9975 primary containment vessel (PCV). SRS currently plans to evacuate the PCV and backfill with argon. Because of the installed HEPA filters and the screw-top lid on the inner can, the entire contents of the PCV will be evacuated and backfilled. This operation is expected to reduce the $\mathrm{O}_{2}$ concentration inside the PCV to less than 5 vol \%.

Concerns relative to the long-term storage of the $\mathrm{NpO}_{2}$ are the potential for container pressurization and/or the formation of $\mathrm{H}_{2}$ as a result of radiolytic decomposition of moisture that is sorbed on the oxide. To address these concerns, radiolysis experiments were conducted at ORNL on $\mathrm{NpO}_{2}$ using both gamma and alpha radiation sources. Samples of $\mathrm{NpO}_{2}$ were prepared by the method expected to be used at SRS (i.e., oxalate precipitation and calcination). Moisture was added to the samples to simulate the water uptake by the sample.

For the gamma radiolysis experiments, both $\mathrm{a}^{60} \mathrm{Co}$ source (dose rate $~ 80,000 \mathrm{rad} / \mathrm{h}$ ) and spent nuclear fuel elements from the High Flux Isotope Reactor (dose rate $10^{7}-10^{8} \mathrm{rad} / \mathrm{h}$ ) were used. The alpha radiolysis experiments were performed by spiking neptunium samples with ${ }^{244} \mathrm{Cm}$ and co-precipitating the curium with the neptunium. The dose rate for the alpha radiolysis experiments is about 70 times that expected for the SRS material, which contains about $500 \mathrm{ppm}{ }^{238} \mathrm{Pu}$. Hence, the typical irradiation time of about six months for this material represents about 35 years irradiation of SRS material.

\subsubsection{Water Sorption Experiments}

The results for the water sorption on the sample prepared at $650^{\circ} \mathrm{C}$ are shown in Fig. 4.2. This figure depicts the weight gain (i.e., amount of water sorption) of the $\mathrm{NpO}_{2}$ sample as a function of time. A similar behavior was seen for the sample prepared at $800^{\circ} \mathrm{C}$. As can be seen from Fig. 4.2, the $\mathrm{NpO}_{2}$ is unlikely to absorb significant water under conditions of $60 \%$ relative humidity. This knowledge will aid in setting the acceptable moisture content range for SRS.

\subsubsection{Results From Gamma Radiolysis}

In general, for the samples with $1 \%$ moisture or less, the gamma radiolysis experiments showed an overall pressure decrease as the $\mathrm{O}_{2}$ over the sample was consumed. Small amounts of $\mathrm{H}_{2}(<1 \mathrm{vol} \%)$ were produced for doses up to 600 MGy (1 Gy = $100 \mathrm{rad})$. Based on these results, it is clear that gamma radiolysis will not be significant in the storage of the $\mathrm{NpO}_{2}$. 


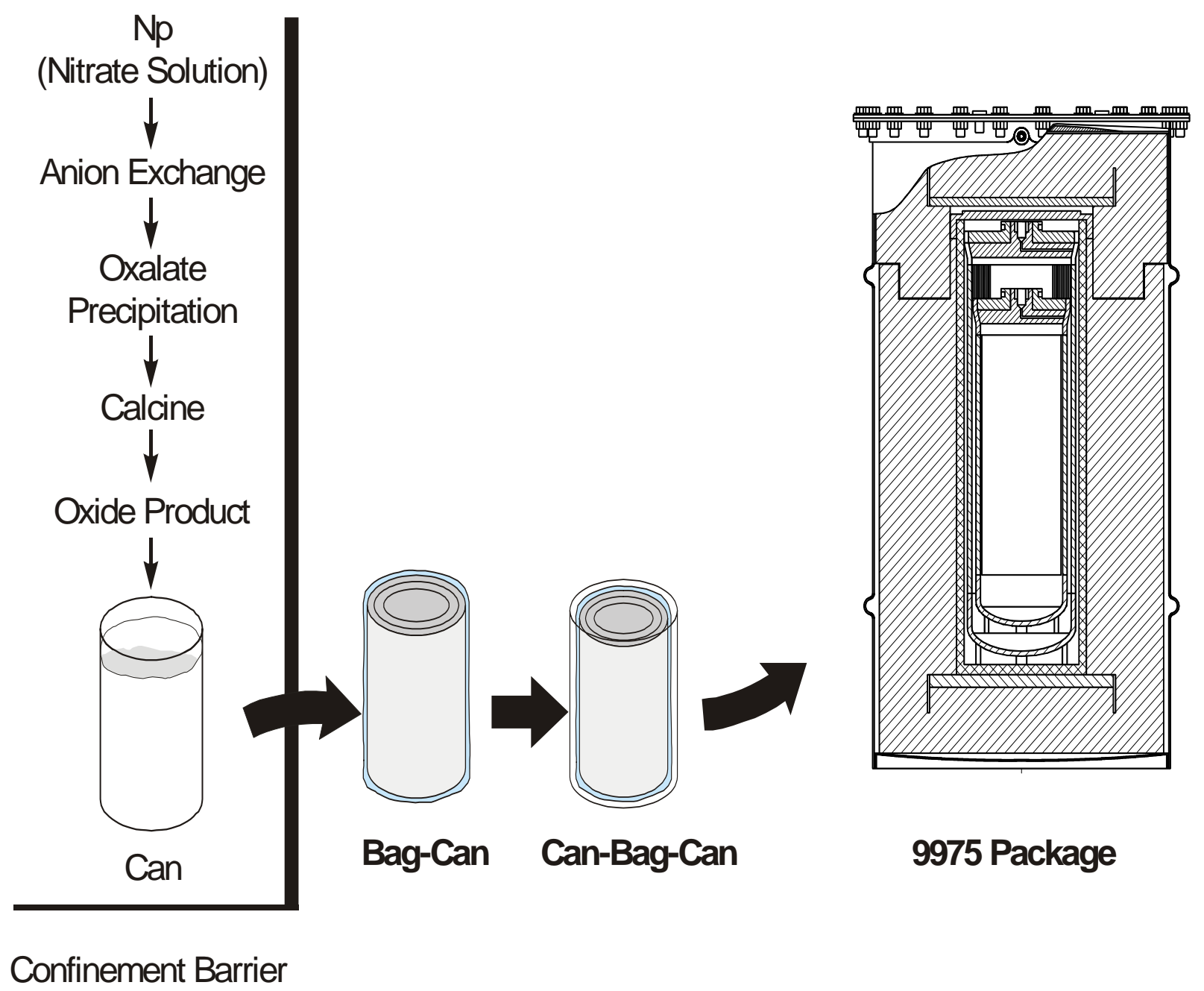

Fig. 4.1. Schematic depiction of neptunium processing and packaging. 

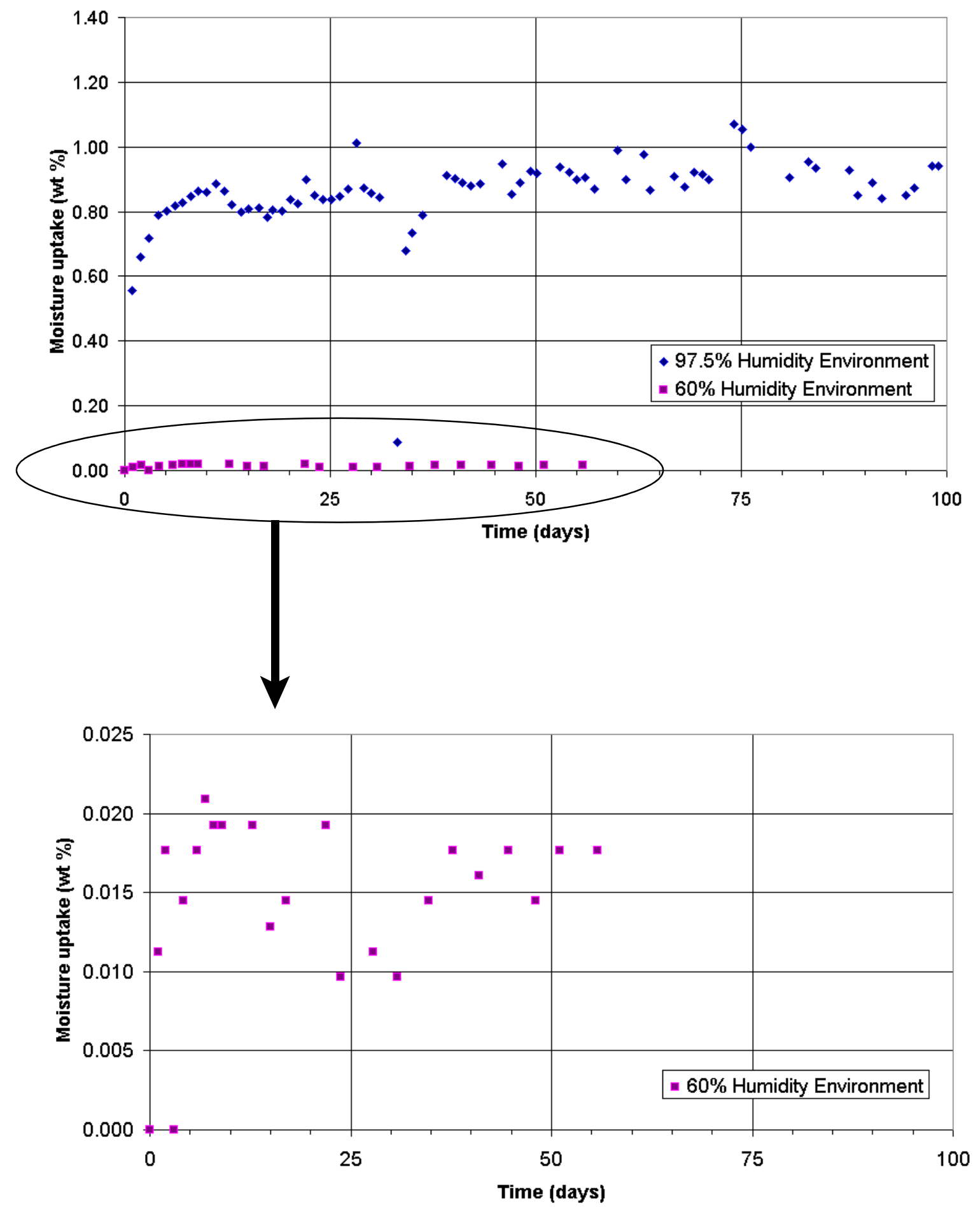

Fig. 4.2. Moisture uptake data for $\mathrm{NpO}_{2}$ prepared at $650^{\circ} \mathrm{C}$. 


\subsubsection{Results From Alpha Radiolysis}

The alpha radiolysis experiments exhibited behavior typical of many radiolysis experiments, i.e., the pressure over the sample (or the damage limit to the sample itself) reaches a steady-state plateau (see Fig. 4.3). The steady-state plateau is clear evidence for a significant back reaction (i.e., the recombination of radiolytic products), where the forward reaction (i.e., the radiolytic decomposition of water) is equal to the back reaction.

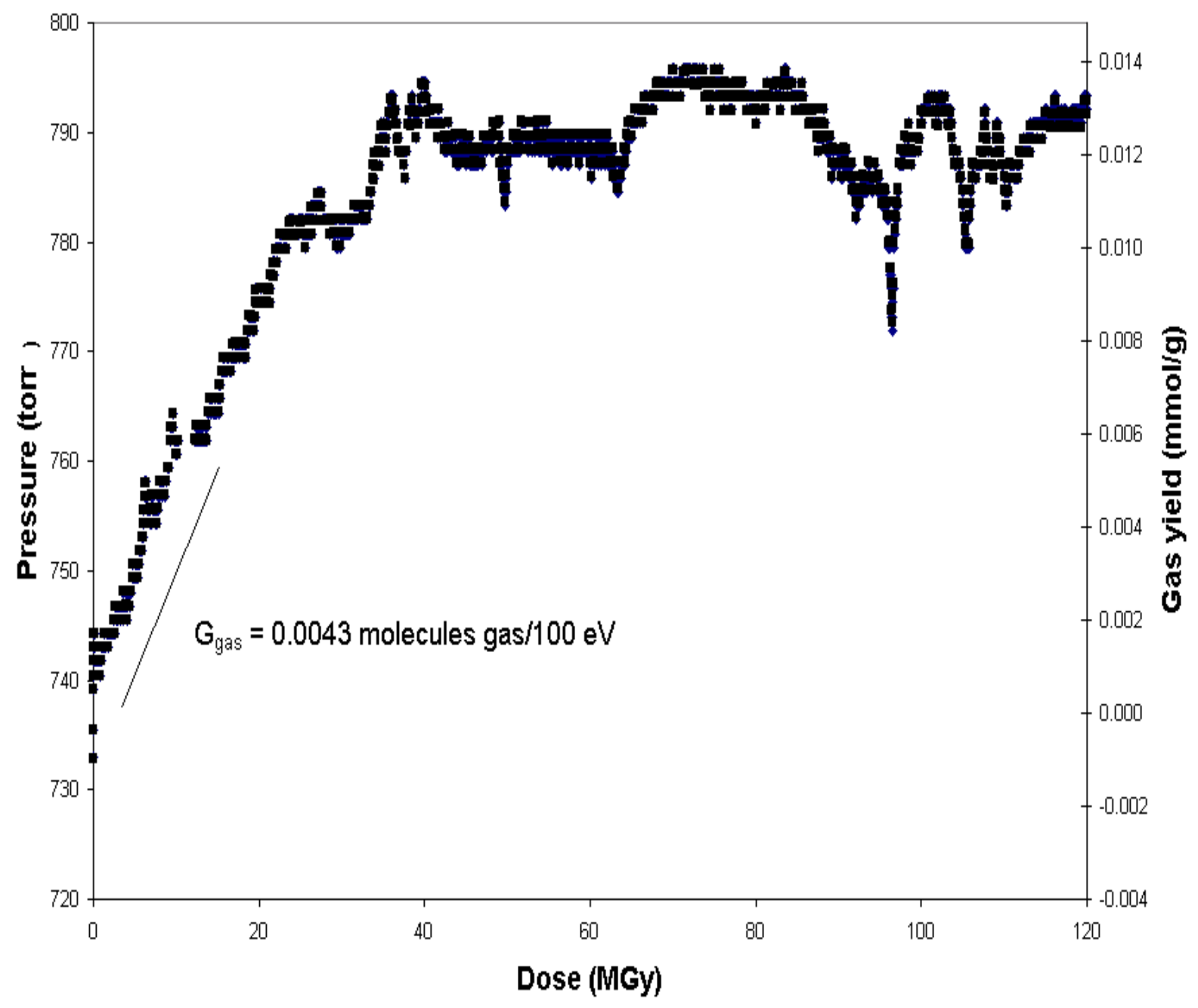

Fig. 4.3. Pressure and gas yield as a function of dose for a $\mathrm{NpO}_{2}$ sample containing $0.5 \mathrm{wt} . \% \mathrm{H}_{2} \mathrm{O}$ and that was spiked with ${ }^{244} \mathrm{Cm}$. 
The experimental results provide a means to quantify parameters related to the forward and back reactions. The forward reaction can be described in terms of a "G-value," where G is defined as the number of molecules of a species produced or destroyed) per $100 \mathrm{eV}$ of energy deposited in the sample. The back reaction can be described in terms of a rate constant, $k$, and the concentrations of the radiolytic products. The following kinetic expression describes the rate of change of the $\mathrm{H}_{2}$ concentration (or equivalently, pressure) in the free volume surrounding the sample.

$$
\frac{d\left[H_{2}\right]}{d t}=\frac{\dot{E} G_{H 2}}{6.0210^{23} V_{\text {void }}}-k\left[H_{2}\right]^{2}\left[O_{2}\right]
$$

where

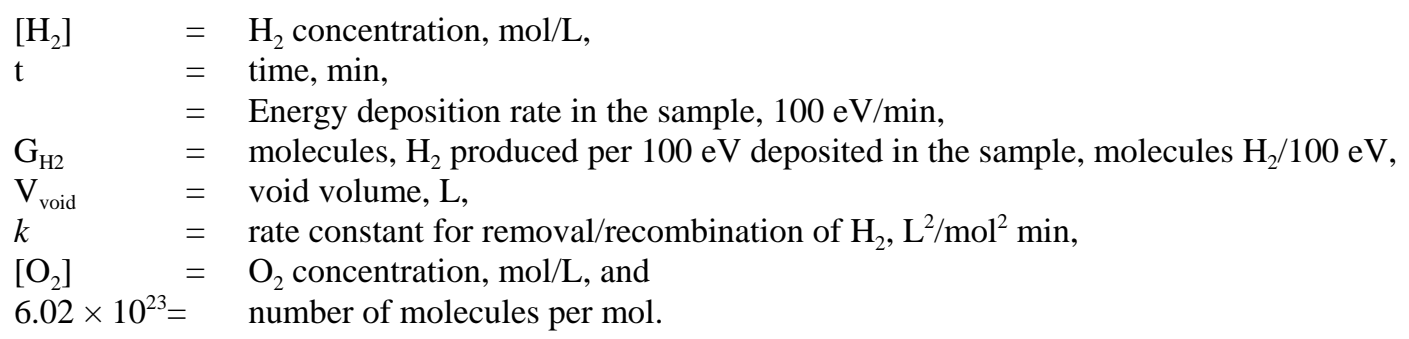

A similar expression can be written for the $\mathrm{O}_{2}$ concentrations.

The data from the alpha radiolysis experiments can be used to measure $\mathrm{G}_{\mathrm{H} 2}, \mathrm{G}_{02}$, and $k$. The $\mathrm{G}$-values are evaluated from the initial pressure rise in the sample container, because the back reactions are negligible at low concentrations. The reaction rate constant, $k$, is evaluated from the steady state concentrations of $\mathrm{H}_{2}$ and $\mathrm{O}_{2}$.

For the case where $\mathrm{NpO}_{2}$ initially contained 0.5 wt. $\% \mathrm{H}_{2} \mathrm{O}$, the kinetic parameters are presented in Table 4.1. These kinetic parameters can be used to calculate the pressure in the container as a function of dose (or equivalently, time). Figure 4.4 shows the good agreement between the experimental data and the values calculated by the kinetic expression. Table 4.1 Kinetic Parameters for the Forward and Back Reactions
For the Alpha Radiolysis of $\mathrm{Npo}_{2}$ Containing $0.5 \mathrm{Wt} \% \mathrm{H}_{2} \mathrm{O}$

\begin{tabular}{cl}
\hline $\mathrm{G}_{\mathrm{H} 2}$ & 0.0029 molecules $\mathrm{H}_{2} / 100 \mathrm{eV}$ \\
$\mathrm{G}_{02}$ & 0.0014 molecules $\mathrm{O}_{2} / 100 \mathrm{eV}$ \\
$k$ & $1.77 \mathrm{~L}^{2} / \mathrm{mol}^{2} \mathrm{~min}$ \\
\hline
\end{tabular}




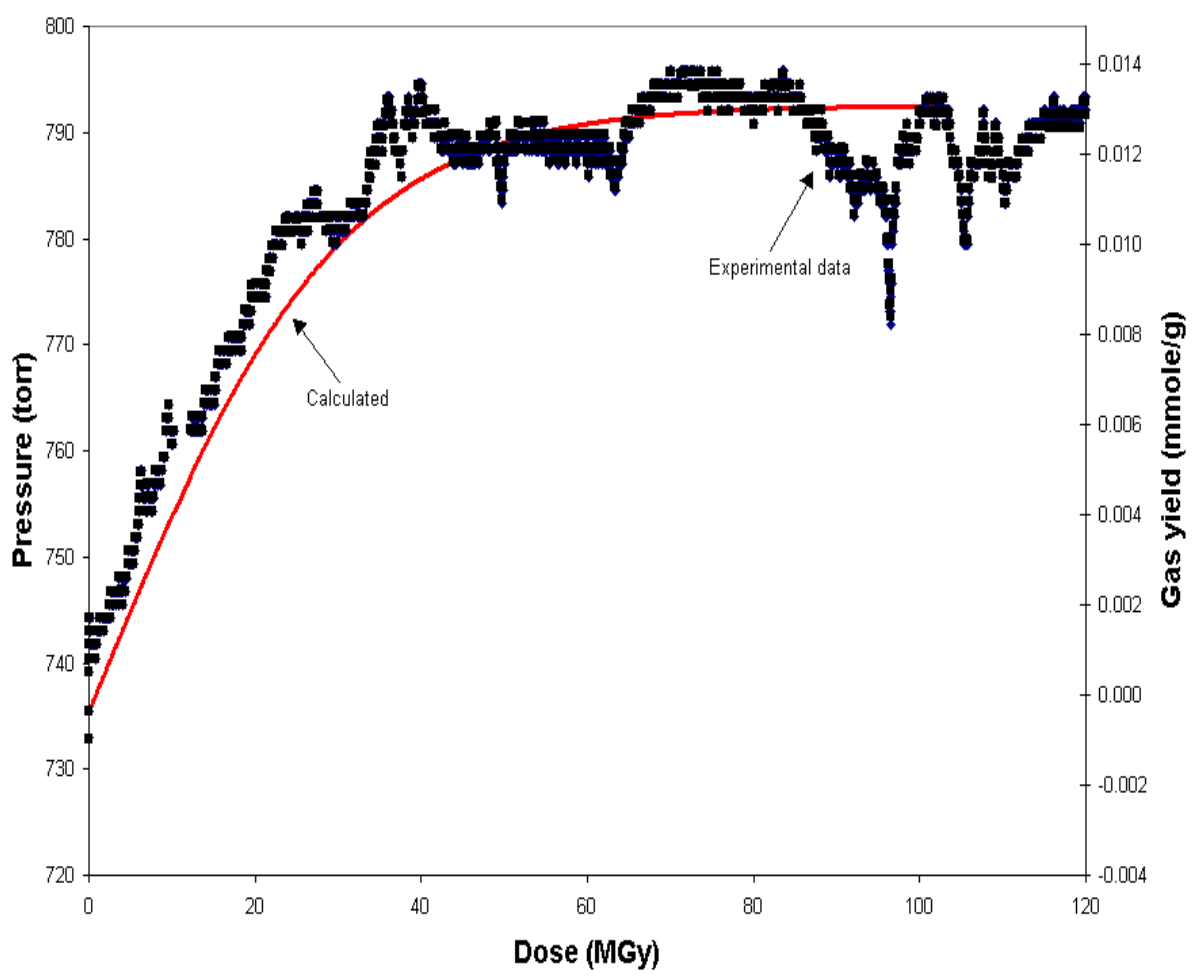

Fig. 4.4. Comparison of experimental data and kinetic model calculations for a $\mathrm{NpO}_{2}$ sample containing 0.5 wt. $\mathrm{H}_{2} \mathrm{O}$ and that was spiked with ${ }^{244} \mathrm{Cm}$.

The kinetic model, which is based on experimental data, can be used to predict the pressure and gas composition for $\mathrm{NpO}_{2}$ in other storage configurations (e.g., a different void volume and radiation source term).

To evaluate the radiolytic gas generation inside the proposed $\mathrm{NpO}_{2}$ storage container, two cases were analyzed: (1) the material is packaged in air and (2) the PCV and its contents are evacuated and backfilled with argon such that the $\mathrm{O}_{2}$ content is $5 \mathrm{vol} . \%$. In each case it was assumed that the $6 \mathrm{~kg} \mathrm{NpO}_{2}$ contained $0.5 \mathrm{wt} \% \mathrm{H}_{2} \mathrm{O}$. The results of the analysis are shown in Fig. 4.5. Note that in each case the $\mathrm{H}_{2}$ concentration at steady state is less than 4 vol.\%, the lower flammability limit for $\mathrm{H}_{2}$ in air. The amount of $\mathrm{H}_{2}$, even if reacted, would result in an extremely small energy release. From the experimental results, and the extension of these results to the proposed storage configuration by use of the kinetic equation, it is clear the $\mathrm{NpO}_{2}$ with $\# 0.5$ wt.\% $\mathrm{H}_{2} \mathrm{O}$ will be safe for long-term storage with respect to radiolytic gas generation. 


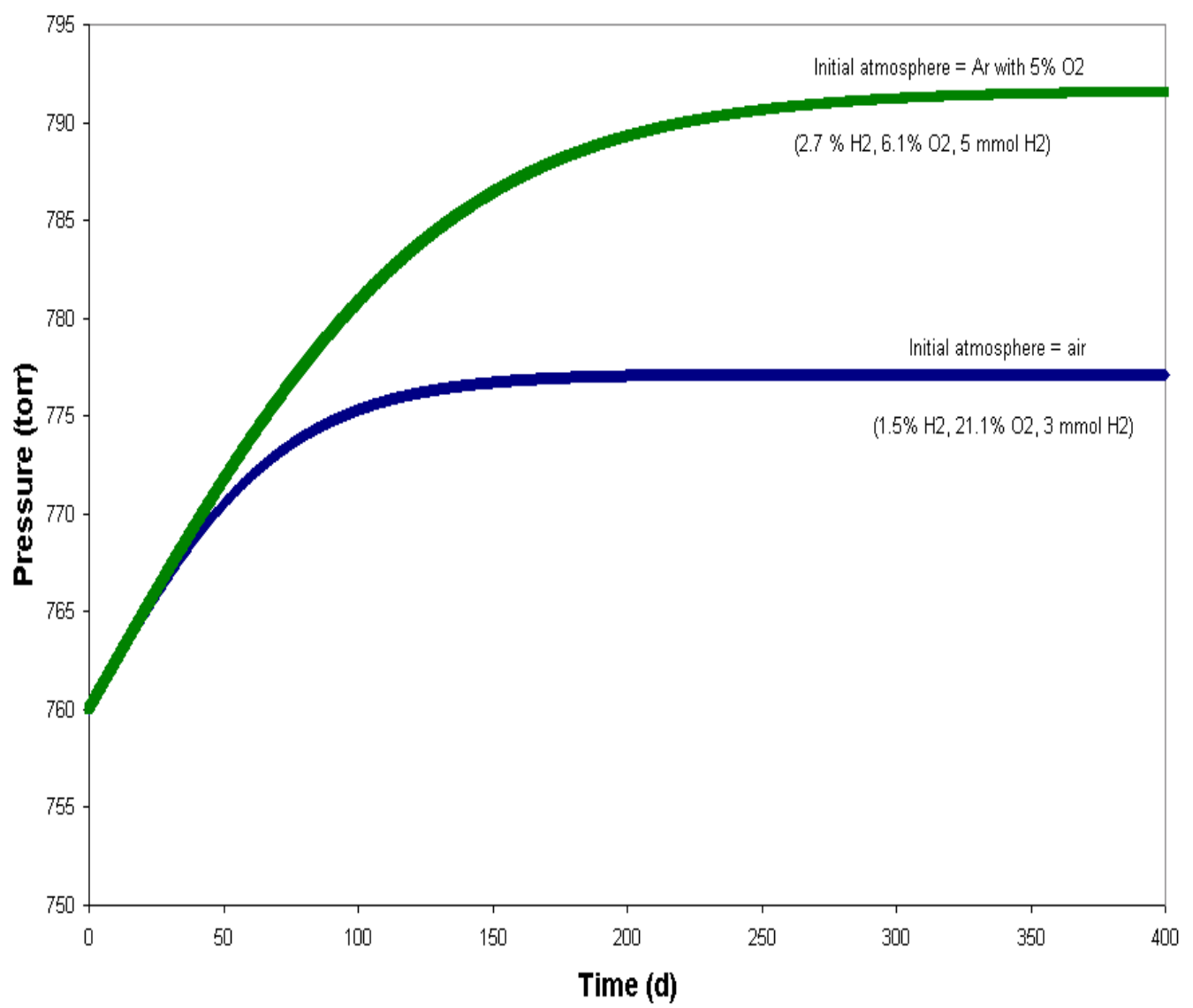

Fig. 4.5. Calculated pressure as a function of time inside the PCV for $6 \mathrm{~kg}$ of $\mathrm{NpO}_{2}$ containing $500 \mathrm{ppm}{ }^{238} \mathrm{Pu}$ (Np basis) and 0.5 wt. $\% \mathrm{H}_{2} \mathrm{O}$ (void volume inside $\mathrm{PCV}=4.62 \mathrm{~L}$ ).

\subsection{ARRAY TARGET POST-IRRADIATION EXAMINATION}

Nine of the 14 targets irradiated in the ATR were segmented and the $\mathrm{NpO}_{2}$ pellets were removed for radiochemical analysis. The following sections describe the targets and the analyses.

\subsubsection{Array Target Description}

The array targets consisted of aluminum tubing that contained three $\mathrm{NpO}_{2}-\mathrm{Al}$ pellets and a dosimeter package. The development work for the fabrication of the targets is described in detail in Ref. 1. The pellets were prepared by mixing the desired amount of $\mathrm{NpO}_{2}$ with aluminum powder and then pressing the mixture to the desired dimensions and density. Pellets were prepared that contained 10 and $20 \mathrm{vol} \% \mathrm{NpO}_{2}$. The pellets were compressed to $90 \%$ theoretical density. After pressing, the pellets were fired at $350^{\circ} \mathrm{C}$, under vacuum, for three hours to remove stearic acid, which served as a lubricant in the die press. The dosimeter package consisted of a $\mathrm{NpO}_{2}$ wire that was contained within a vanadium can. A schematic of the target configuration is shown in Fig. 4.6. Each target had a pellet section, containing three pellets, and a dosimeter section, containing one dosimeter package. Seven of the targets were loaded with $10 \mathrm{vol} \% \mathrm{NpO}_{2}$ pellets, while the other seven were loaded with $20 \mathrm{vol} \% \mathrm{NpO}_{2}$ pellets. The pellet section and dosimeter section were separated by an aluminum spacer, and they were located in the top half of the target. The bottom half of the target contained an aluminum tube spacer that acted as a plenum for fission gas expansion. The plenum was separated from the pellets by a porous aluminum spacer, which allowed fission product gases to expand into the plenum. The pellet and 


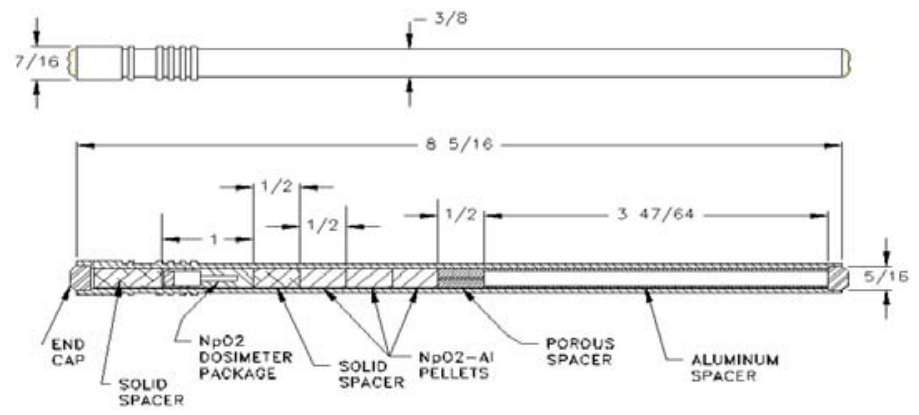

Fig. 4.6. Schematic of aluminum clad target that contains three $\mathrm{NpO}_{2}-\mathrm{Al}$ pellets and a dosimeter package.

dosimeter sections can be removed from a target by cutting through the solid spacers, which results in a pellet section, a dosimeter section, a top aluminum spacer section, and aluminum tube spacer section.

\subsubsection{ATR Irradiation}

The 14 targets were shipped to the INL where they were loaded into an aluminum basket (similar to that depicted in Fig. 4.7), thereby forming two arrays as depicted in Fig. 4.8. The seven $10 \mathrm{vol} \%$ targets comprised the upper array, while the seven $20 \mathrm{vol} \%$ targets formed the lower array. Note that, as shown in Fig. 4.8, the targets were aligned along an axis relative to the center of the reactor. This orientation was selected to aid in the evaluation of self-shielding by the targets. The arrays were irradiated for two cycles in position B-10 of the ATR (Fig. 4.9), which is a 1.5-in.-diam. hole near two control drums on the East side of the reactor.

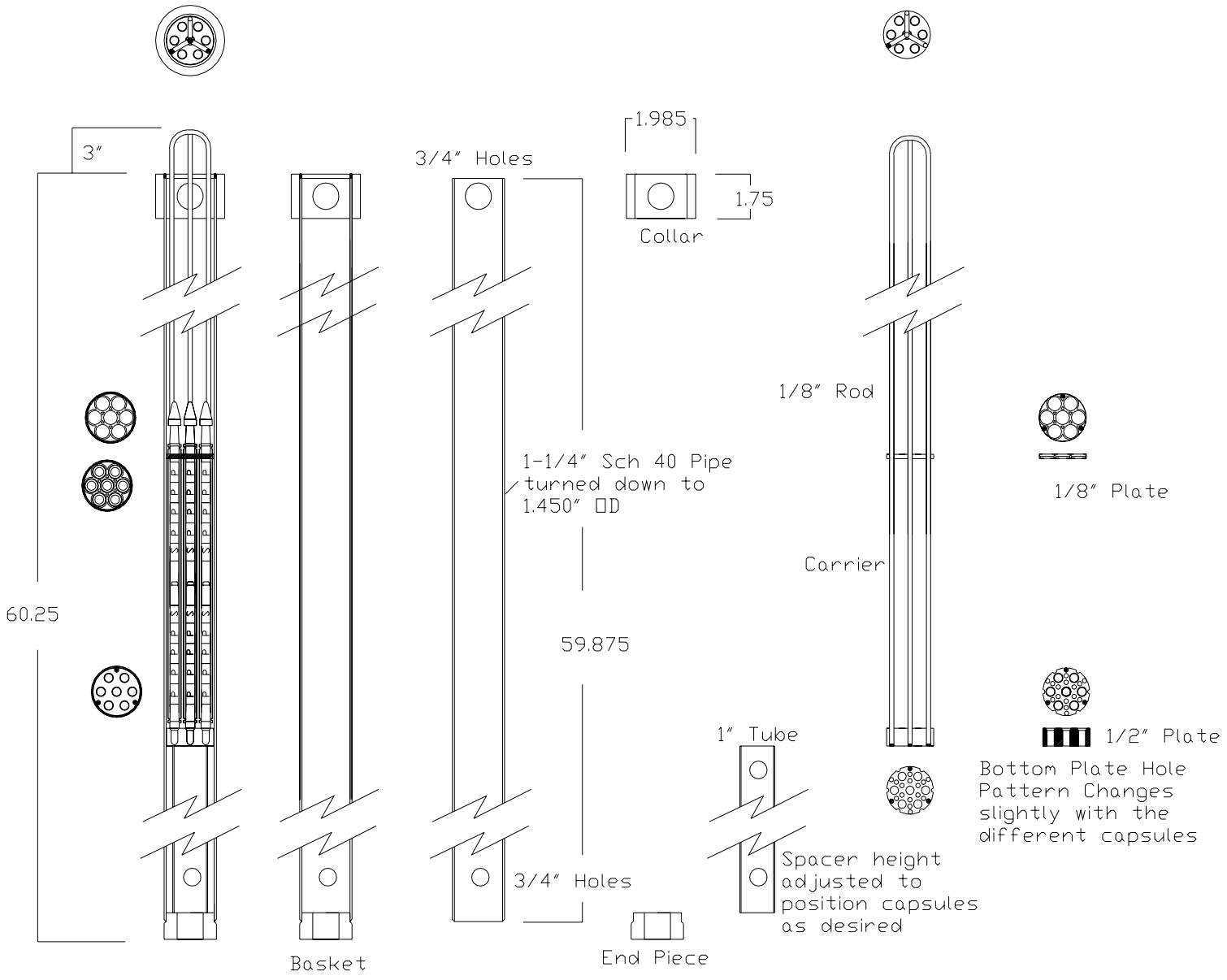

Fig. 4.7. Depiction of aluminum basket similar to that used in the array target irradiations. 


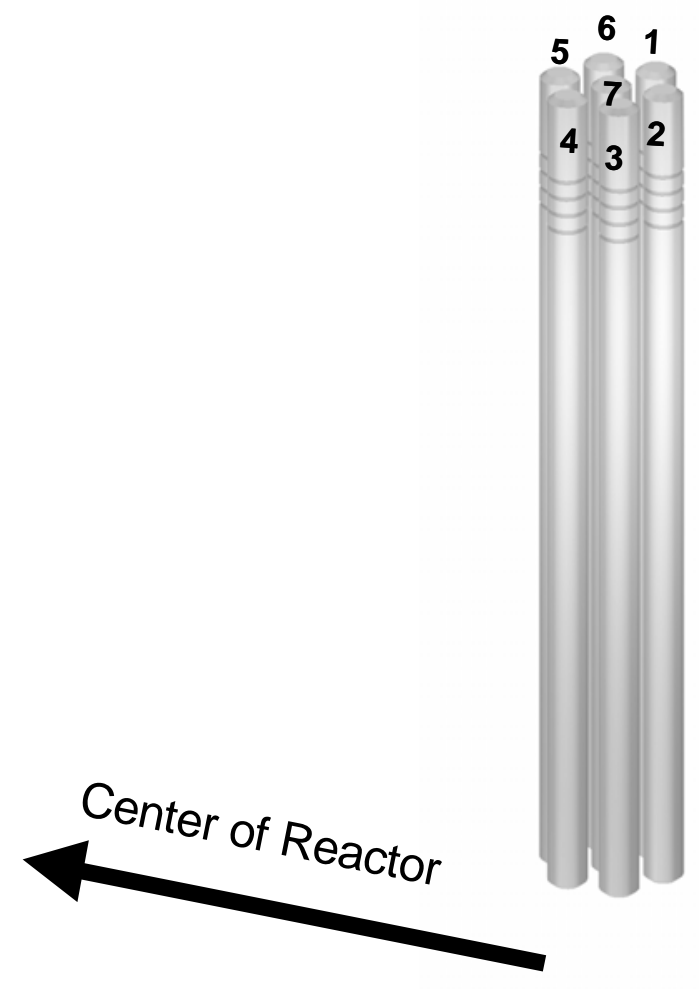

Upper B-10 Position
10 vol.\% Np Targets

$1=\mathrm{MK}-10.3$

$2=M K-10.4$

$3=\mathrm{MK}-10.5$

$4=\mathrm{MK}-10.0$

$5=\mathrm{MK}-10.1$

$6=\mathrm{MK}-10.2$

$7=\mathrm{MK}-10.6$

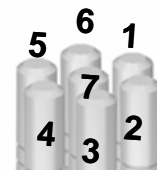

\section{B-10 Position}

Lower B-10 Position

20 vol.\% Np Targets

$1=\mathrm{MK}-20.3$

$2=M K-20.4$

$3=\mathrm{MK}-20.5$

$4=M K-20.0$

$5=\mathrm{MK}-20.1$

$6=\mathrm{MK}-20.2$

$7=\mathrm{MK}-20.6$

Fig. 4.8. Depiction of configuration of the $10 \mathrm{vol} \%$ and $20 \mathrm{vol} \% \mathrm{NpO}_{2}$ arrays relative to the center of the ATR core. 
ORNL DWG 98C-221

\section{Cross Section of the INEEL/Advanced Test Reactor Depicting Irradiation Facilities}

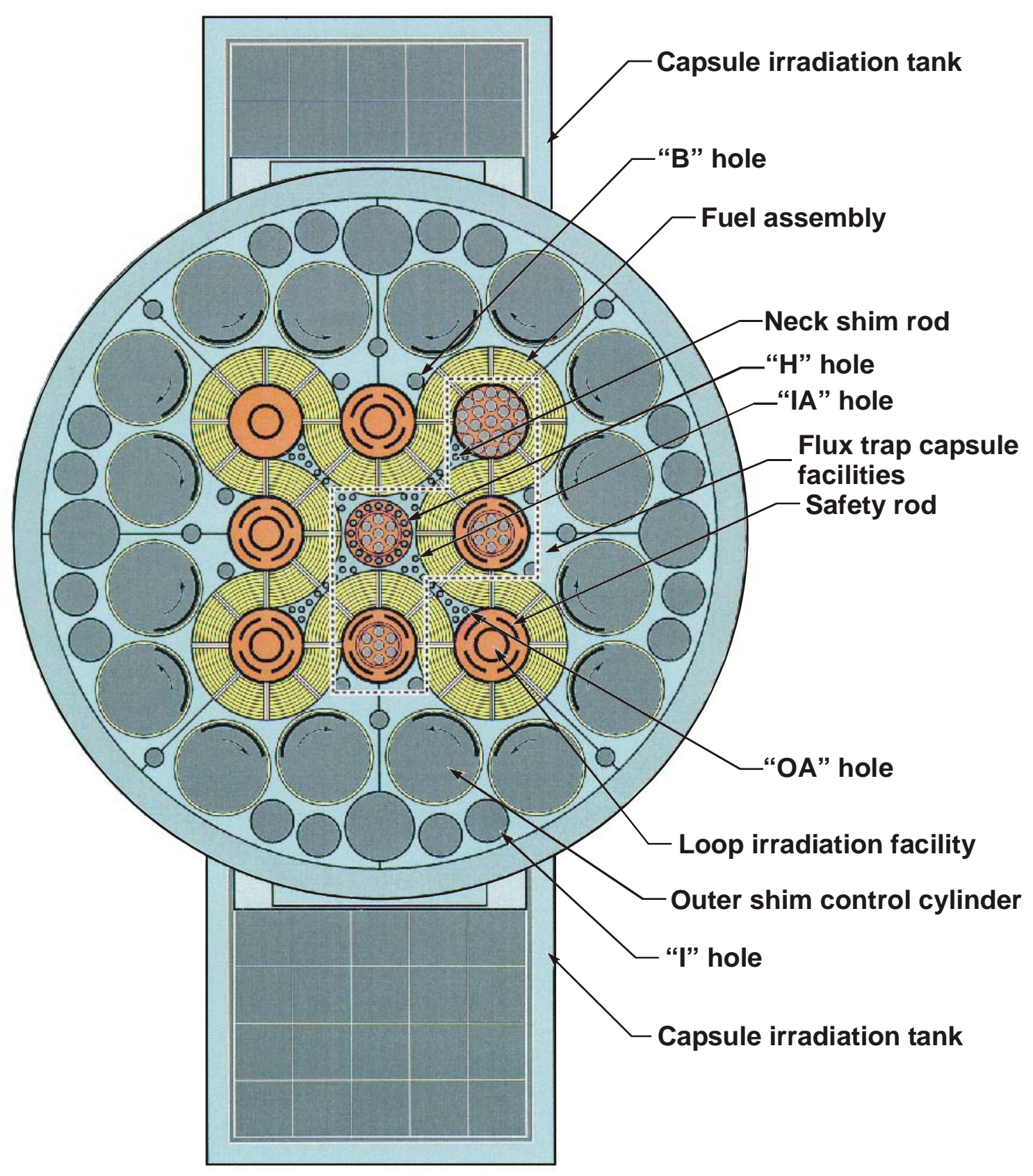

Fig. 4.9. Cross section of the ATR core showing position B-10, which was used in the array target irradiation. 


\subsubsection{Results and Discussion}

The analytical results from each dissolution sample were used to calculate the amount of Np converted to Pu, the amount of ${ }^{238} \mathrm{Pu}$ recovered, and the ${ }^{236} \mathrm{Pu}$ produced. The results of the analyses are summarized in Table 4.2. To provide some insight into the effect of position and target self-shielding, results are presented in terms of the relative power. The relative power reported for each target was calculated by dividing the neutron flux at a target by the average flux in the region. Note that this calculation was performed for one point in time during the irradiation, and hence it is representative of only a particular control drum configuration. Calculations are being performed to establish the relative power based on the total fluence at each target. However, it is not expected that the relative powers will change significantly. The quantities reported in Table 4.2 are briefly defined in the following paragraph.

Table 4.2 Summary of Results for Array Target Analysis

\begin{tabular}{|c|c|c|c|c|c|}
\hline \multirow{2}{*}{$\begin{array}{c}\text { Target } \\
\text { number }\end{array}$} & \multirow{2}{*}{$\begin{array}{c}\text { Relative } \\
\text { Power }\end{array}$} & \multirow{2}{*}{$\begin{array}{c}{ }^{238} \mathrm{Pu} / \mathrm{Total} \\
\mathrm{Pu} \\
(\mathrm{wt} \%) \\
\end{array}$} & \multicolumn{2}{|c|}{ Conversion (mol \%) } & \multirow{2}{*}{$\begin{array}{c}{ }^{236} \mathrm{Pu} \text { at discharge } \\
(\mathrm{ppm})\end{array}$} \\
\hline & & & $\mathrm{Np}$ to $\mathrm{Pu}$ & $\mathrm{Np}$ to FP & \\
\hline MK-10.4 & 0.49 & 89.99 & 11.14 & 0.06 & $3.26 \pm 8.5 \%$ \\
\hline MK-10.6 & 0.91 & 87.81 & 12.76 & 0.09 & $3.86 \pm 5.1 \%$ \\
\hline MK-10.2 & 1.32 & 86.06 & 13.52 & 0.09 & $3.30 \pm 11.2 \%$ \\
\hline MK-10.1 & 1.7 & 84.80 & 16.34 & 0.18 & $2.96 \pm 6.2 \%$ \\
\hline MK-20.4 & 0.46 & 90.09 & 10.08 & 0.05 & $6.24 \pm 2.5 \%$ \\
\hline MK-20.5 & 0.72 & 87.36 & 12.18 & 0.08 & $4.58 \pm 6.3 \%$ \\
\hline MK-20.6 & 0.81 & 88.51 & 11.69 & 0.08 & $5.36 \pm 3.7 \%$ \\
\hline MK-20.2 & 1.25 & 87.17 & 14.69 & 0.10 & $3.58 \pm 2.7 \%$ \\
\hline MK-20.1 & 1.72 & 84.68 & 14.11 & 0.15 & $4.29 \pm 6.4 \%$ \\
\hline
\end{tabular}

The weight percentage of ${ }^{238} \mathrm{Pu}$ (on the basis of total plutonium) is shown. The conversion of neptunium to both plutonium and fission products is calculated by dividing the moles of each of these quantities by the initial moles of neptunium. The neptunium and plutonium loss to waste are the weight percentage of the recovered neptunium and plutonium that are in the caustic dissolution stream. The ${ }^{236} \mathrm{Pu}$ reported is the amount (ppm on a total Pu basis) present at discharge of the target from the reactor. This amount was calculated from the measured concentration of the processed target and the time since discharge.

The isotopic distribution of the fission products is shown for the caustic dissolution and the acid. These amounts are reported in terms of ppm of the ${ }^{238} \mathrm{Pu}$ produced and can therefore be used to estimate fission product concentrations in waste streams for a particular ${ }^{238} \mathrm{Pu}$ production rate. A summary of the data measured for the dosimeters is presented in Table 4.3. 
Table 4.3 Summary of Dosimeter Data

\begin{tabular}{ccccc}
\hline $\begin{array}{c}\text { Target ID for } \\
\text { dosimeter }\end{array}$ & $\begin{array}{c}\text { Relative } \\
\text { power }\end{array}$ & $\begin{array}{c}{ }^{238} \mathrm{Pu} / \text { Total Pu } \\
\text { (wt \%) }\end{array}$ & $\begin{array}{c}\text { Conversion of } \\
\text { Np to Pu } \\
\text { (mol \%) }\end{array}$ & $\begin{array}{c}{ }^{236} \mathrm{Pu} \text { at } \\
\text { discharge (ppm) }\end{array}$ \\
\hline MK-10.4 & 0.49 & 88.46 & 11.07 & $2.76 \pm 6.2 \%$ \\
MK-10.6 & 0.91 & 86.75 & 14.11 & $2.39 \pm 5.0 \%$ \\
MK-10.2 & 1.32 & $a$ & $a$ & $a$ \\
MK-10.1 & 1.7 & 84.12 & 12.47 & $3.79 \pm 4.2 \%$ \\
MK-20.4 & 0.46 & 85.76 & 9.62 & $3.55 \pm 5.2 \%$ \\
MK-20.5 & 0.72 & $a$ & $a$ & $a$ \\
MK-20.6 & 0.81 & 83.18 & 13.75 & $4.24 \pm 4.5 \%$ \\
MK-20.2 & 1.25 & 81.56 & 17.81 & $3.33 \pm 6.2 \%$ \\
MK-20.1 & 1.72 & 79.56 & 19.29 & $4.20 \pm 3.7 \%$ \\
\hline
\end{tabular}

${ }^{a}$ Not analyzed.

Figures 4.10-4.12 provide a graphical representation of some of the data as a function of the relative power. In Fig. 4.10, the percentages of $\mathrm{Np}$ converted to plutonium are shown. The percentage of total plutonium that consists of ${ }^{238} \mathrm{Pu}$ is shown in Fig. 4.11. Finally, the ${ }^{236} \mathrm{Pu}$ concentration (ppm on a total Pu basis) is presented in Fig. 4.12.

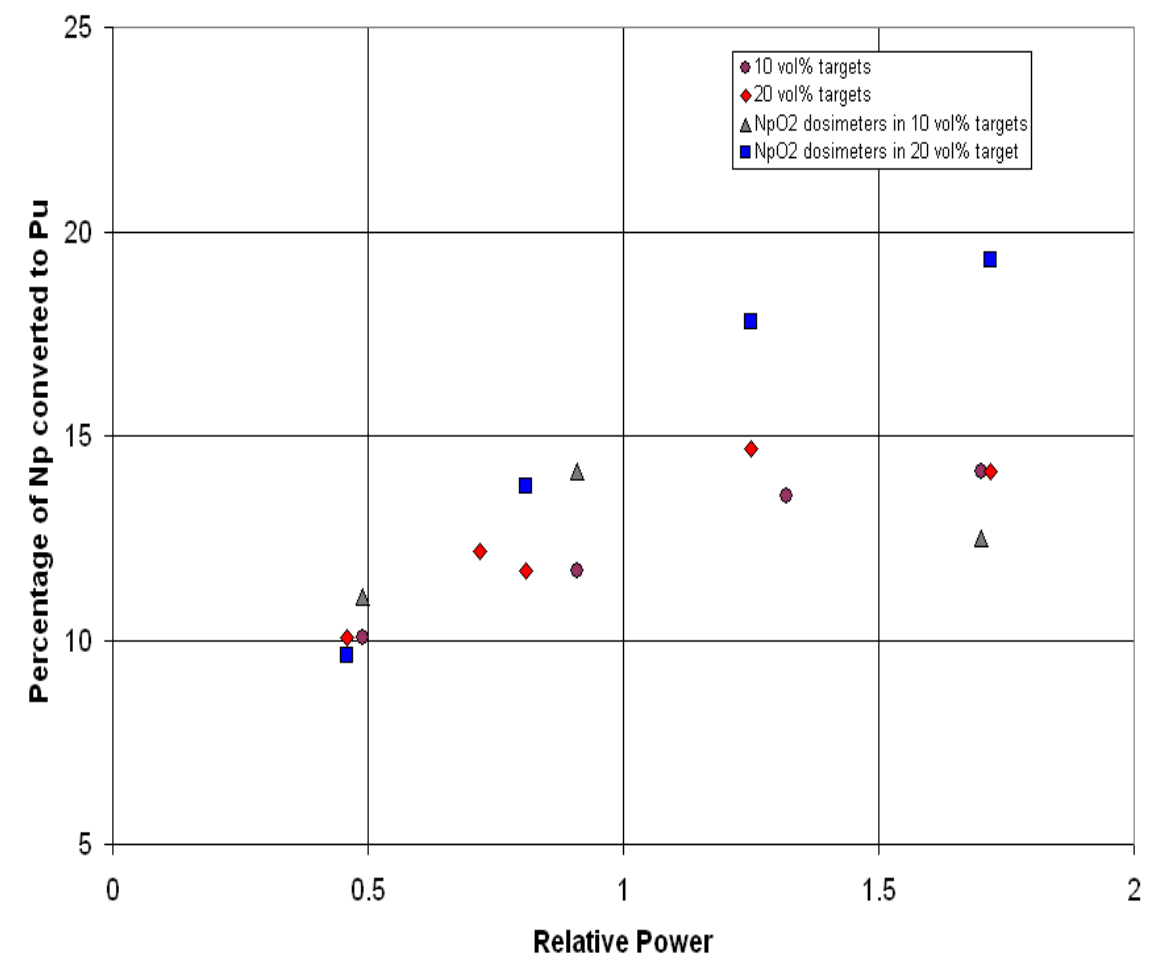

Fig. 4.10. Percentage of neptunium converted to plutonium as a function of relative power for the targets and dosimeters. 


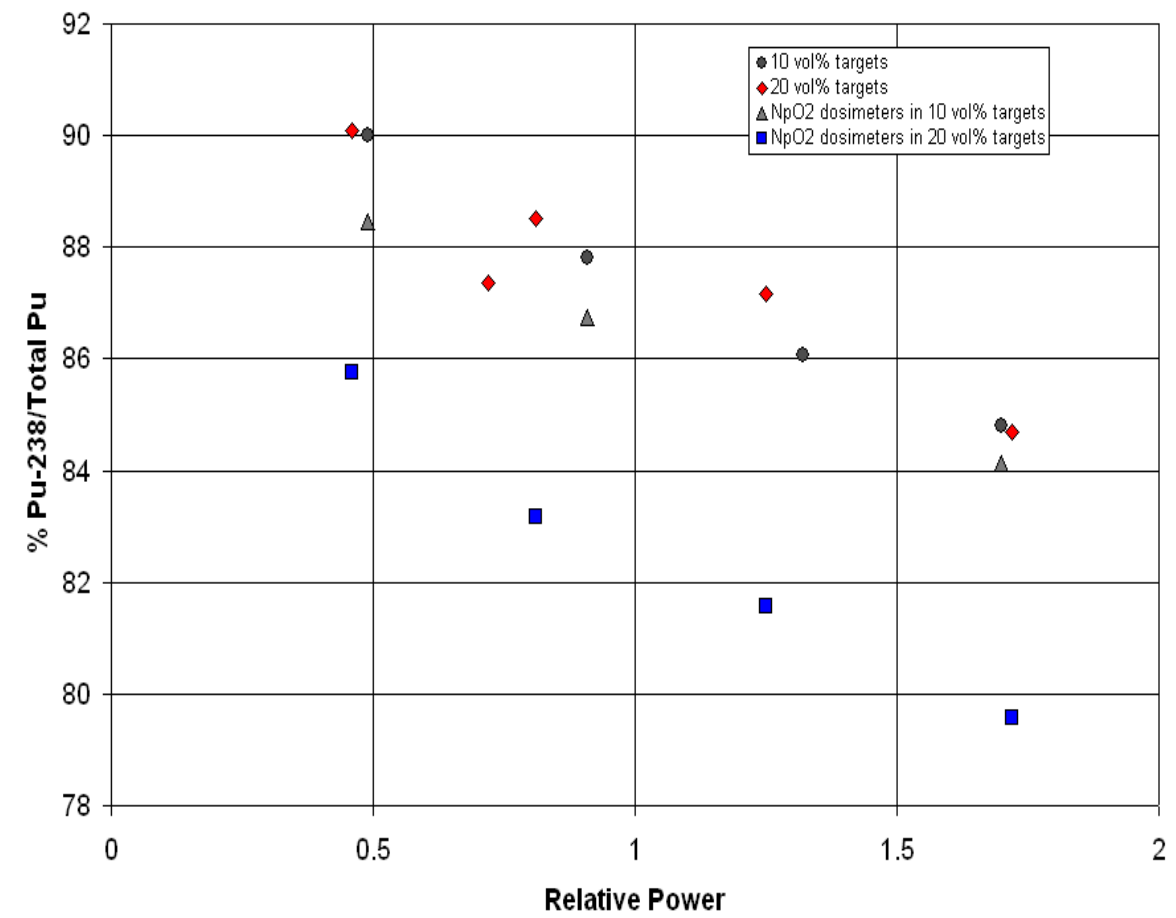

Fig. 4.11. Plutonium-238 production as a percentage of total plutonium production for the targets and dosimeters.

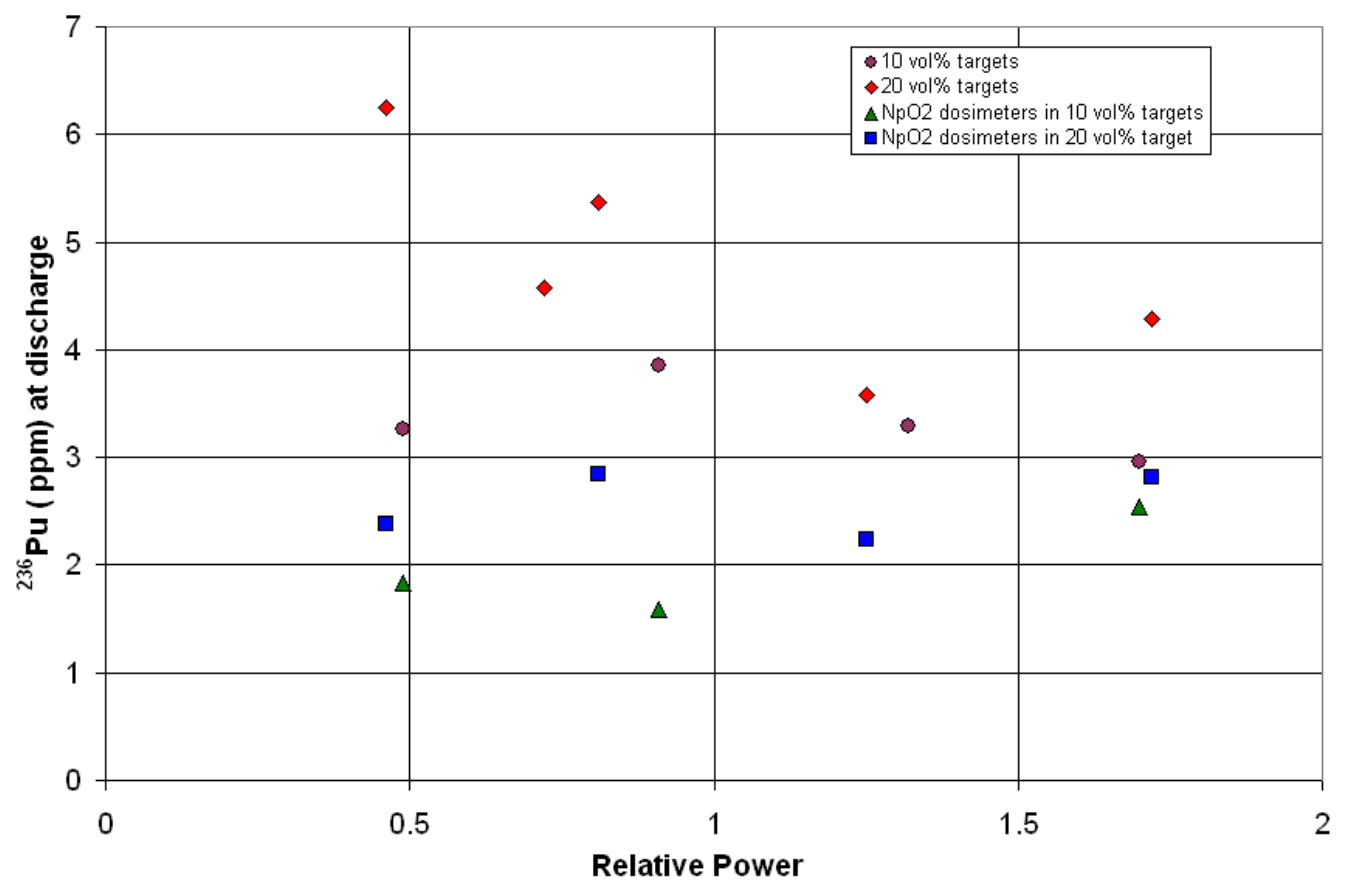

Fig. 4.12. Plutonium-236 content at discharge from the ATR as a function of relative power for the targets and dosimeters. 
Several trends that reflect the different flux (and target self shielding) at the various target positions are evident in the figures. The percentage of neptunium that is converted to plutonium increases with relative power-ranging from about 10 to $16 \mathrm{~mol} \%$ for the pellets. The results for the 10 and $20 \mathrm{vol} \%$ targets are similar. The ${ }^{238} \mathrm{Pu}$ production, as a percentage of total plutonium, generally decreases with increasing relative power. This value ranged from about 85 to $90 \mathrm{wt} \%$ for the pellets. The specification for ${ }^{238} \mathrm{Pu}$ production is $82 \mathrm{wt} \%$, as of the date of processing. Again, the 10 and 20 vol \% targets provided similar results. In Fig. 4.12, the ${ }^{236} \mathrm{Pu}$ production at discharge tends to decrease with increasing relative power. Additionally, the ${ }^{236} \mathrm{Pu}$ production is higher in the $20 \mathrm{vol} \%$ pellets than in the $10 \mathrm{vol} \%$ targets. The ${ }^{236} \mathrm{Pu}$ production in the pellets ranged from about 3 to $6 \mathrm{ppm}$. The specification for ${ }^{236} \mathrm{Pu}$ is $2 \mathrm{ppm}$, as of the date of precipitation. Hence, these targets would require a cooling period of 1.7 to 4.5 years. 
INTERNAL DISTRIBUTION

1. M. C. Carpenter

2. E. P. George

3. J. S. Ivey

4-6. J. F. King

7. E. K. Ohriner
8. G. R. Romanoski

9. G. B. Ulrich

10. R. M. Wham

11. Laboratory Records

\section{EXTERNAL DISTRIBUTION}

12-20. U. S. DEPARTMENT OF ENERGY, NE-50/Germantown Building, 1000 Independence Avenue, SW, Washington, District of Columbia 20585-1290
J. Dowicki
A. S. Mehner
D. Cairns-Gallimore
L. L. Rutger
L. Edgerly
E. J. Wahlquist
T. A. Frazier
R. L. Wiley
R. R. Furlong

21. DEPARTMENT OF ENERGY, Albuquerque Field Office, P.O. Box 5400, Albuquerque, NM 87115 R. L. Holton

22-23. DEPARTMENT OF ENERGY, Oak Ridge Operations Office, Bldg. 4500N, Oak Ridge, TN 37831

L. W. Boyd, Mail Stop 6390

S. R. Martin, Jr., Mail Stop 6269

24. DEPARTMENT OF ENERGY, Los Alamos Area Office, 528 35th Street, Los Alamos, NM 87544 R. J. Valdez

25. DEPARTMENT OF ENERGY, Savannah River Operations Office, Bldg. 703F, P.O. Box A, Aiken, SC 29802

S. W. McAlhaney

26. ARGONNE NATIONAL LABORATORY-WEST, P. O. Box 2528, Building 774, Idaho Falls, ID 83403

S. G. Johnson

27. LOCKHEED MARTIN ASTRONAUTICS, P.O. Box 8555, Philadelphia, PA 19101

R. M. Reinstrom

28. LOS ALAMOS NATIONAL LABORATORY, P.O. Box 1663, NMT-9, MS E502, Los Alamos, NM 87545

Marty Bowidowicz

29-30. ORBITAL SCIENCES CORPORATION, INC., 20030 Century Blvd., Suite 102, Germantown, MD 20874
R. T. Carpenter
E. A. Skrabek 
31. TEXAS A\&M UNIVERSITY, Center for Space Power, Mail Stop 3118, College Station, TX 77843 M. J. Schuller

32. WESTINGHOUSE ADVANCED TECHNOLOGY BUSINESS AREA, 1310 Beulah Road, Building 401, 2nd Floor, Room 2B01, Pittsburgh, PA 15235

M. O. Smith 